\title{
Analysis on MM5 predictions at Sriharikota during northeast monsoon 2008
}

\author{
D Gayatri Vani*, S Rambabu, M Rajasekhar, G V Rama, B V Apparao and A K Ghosh \\ MET-Facility, Satish Dhawan Space Centre, SHAR, ISRO, Sriharikota 524 124, India. \\ *e-mail: dgayatrivani@gmail.com
}

\begin{abstract}
The Indian northeast monsoon is inherently chaotic in nature as the rainfall realised in the peninsular India depends substantially on the formation and movement of low-pressure systems in central and southwest Bay of Bengal and on the convective activity which is mainly due to the moist north-easterlies from Bay of Bengal. The objective of this study is to analyse the performance of the PSU-NCAR Mesoscale Model Version 5 (MM5), for northeast monsoon 2008 that includes tropical cyclones - Rashmi, Khai-Muk and Nisha and convective events over Sriharikota region, the rocket launch centre. The impact of objective analysis system using radiosonde observations, surface observations and Kalpana-1 satellite derived Atmospheric Motion Wind Vectors (AMV) is also studied. The performance of the model is analysed by comparing the predicted parameters like mean sea level pressure (MSLP), intensity, track and rainfall with the observations. The results show that the model simulations could capture MSLP and intensity of all the cyclones reasonably well. The dependence of the movement of the system on the environmental flow is clearly observed in all the three cases. The vector displacement error and percentage of improvement is calculated to study the impact of objective data analysis on the movement and intensity of the cyclone.
\end{abstract}

\section{Introduction}

The southwest monsoon is the principal rainy season for the Indian subcontinent. But regions like Tamil Nadu and south Andhra receive maximum rainfall during the northeast monsoon (OctoberDecember). This rainfall is mainly due to the tropical cyclones and northeast monsoon activity. Tropical cyclone systems form over warm tropical oceans and develop under favourable atmospheric and oceanic conditions, such as sea surface temperatures greater than $26^{\circ} \mathrm{C}$ with large Coriolis force, high low-level relative vorticity, weak vertical wind shear, moisture in mid troposphere and convective instability (Gray 1975). The cyclones over Bay of Bengal (BOB) are maximum in May, October and November when they have their origin around $10^{\circ} \mathrm{N}$ along the equatorial trough or Inter Tropical Convergence Zone (ITCZ) which retreats from North India to southern edge of BOB (William Gray 1968). The cyclones during post-monsoon period are most devastating especially when they cross coastal states of India and Bangladesh (De Angelis 1976). Numerical models are being used to predict tropical cyclones for the past two to three decades. Many model simulation studies have been carried out on tropical cyclone genesis, track prediction and their intensities. Mohanty et al (2004) simulated the Orissa supercyclone with a single domain at a resolution of $30 \mathrm{~km}$, and their study indicates that MM5 could predict intensification up to $48 \mathrm{hr}$ but underestimated it thereafter. Earlier Patra et al (2000) simulated Tropical cyclones using regional models. Rao and Bhaskar

Keywords. Northeast monsoon; convective activity; tropical cyclone. 
Rao (2003) also reported a good simulation of the Orissa cyclone using Grell, MRF and Simple-Ice schemes for the physical processes, but underestimated the intensity. Braun (2002) carried out a cloud resolving simulation of Hurricane 'BOB' to analyse the storm structure and eye wall buoyancy. Mandal et al (2004) made a study on the impact of parameterization of physical processes on prediction of tropical cyclones over BOB. Recently the very severe cyclonic storm, Nargis, was simulated by Pattnaik and Rama Rao (2009) using WRF model. In tropics, in addition to tropical cyclones, mesoscale convective systems also account for large amount of precipitation. Several studies were carried out for predicting the convective events using mesoscale models (Weisman et al 1997; Done et al 2004; Litta and Mohanty 2008).

Sriharikota (SHAR), the rocket launch centre on the east coast of south peninsular India, generally receives maximum rainfall during $\mathrm{NE}$ monsoon period. For planning and execution of weathercritical launch activities, prediction of weather events like lightning, strong ground winds, rain, etc., play an important role. Daily weather forecast based on Numerical Weather Predictions (NWP) and close weather watch for now-casting is an important activity at Meteorology Facility, SHAR to take go/no-go decision for the planned activities. For this purpose, NCAR MM5 is being operated on 16-node cluster computer to predict weather for the next 24, 48 hours for SHAR region. A detailed description of MM5 is presented by Grell et al (1995). PSLV-C11/Chandrayan-1 launch was scheduled on 22 October, 2008. During this campaign period SHAR experienced convective activity due to onset of NE monsoon. In this study, an attempt has been made to evaluate predictions of the convective events over SHAR region and three cyclones namely Rashmi (25-27 October), Khai-Muk (13-15 November) and Nisha (25-27 November) which developed in BOB in 2008.

\section{Methodology and data used}

MM5 model simulations are carried out for a single domain $\left(10^{\circ} \mathrm{S}-40^{\circ} \mathrm{N} ; 45^{\circ} \mathrm{E}-105^{\circ} \mathrm{E}\right)$ at a horizontal resolution of $27 \mathrm{~km}$ and 23 levels in vertical with time integration of $81 \mathrm{~s}$ for all the three cyclones. For the three convective events, two-way nested domain of $27 \mathrm{~km}$ and $9 \mathrm{~km}$ resolution with time integration of 81 and $27 \mathrm{~s}$ is taken. This is chosen in accordance to the CFL (Couhrant Federal Lewis) criterion that defines the relation between spatial resolution and time integration, in order to avoid computational instability. Betts Miller Scheme (Betts and Miller 1986) is chosen for cumulus parameterization with MRF PBL and the radiative effects due to clouds are considered by Rapid Radiative Transfer Model (RRTM, Mlawer et al 1997). Explicit treatment of cloud water, rainwater, snow and ice is performed using Simple Ice scheme (Jimy Dhudia 1989). The initial and lateral boundary conditions are taken from the National Centre for Environmental Prediction (NCEP) Global Forecast System (GFS) at a resolution of $1^{\circ}(\sim 111 \mathrm{~km})$. A brief configuration of the model is summarized in table 1 .

For the three tropical cyclones of 2008 in BOB, model simulations are made with four initial conditions (IC) for each cyclone. In the case of Rashmi, simulations are carried out from 25th October 00 UTC IC to 26th October 12 UTC IC for every $12 \mathrm{hr}$ interval. For Khai-Muk, simulations are carried out with 00 and 12 UTC IC for 14th and 15th November. Whereas for cyclone Nisha, simulations are made with IC of 00 UTC of 25th, 26th and 27 th, and 12 UTC of 27 th November. In all the above three cases, the model had been integrated for $48 \mathrm{hr}$. For study of convective activity three major events during the onset of northeast monsoon (12th, 16th and 20th October) are considered. The simulations are carried out on the respective days with IC of 00 UTC for 24 hours.

In order to improve the model, initial conditions obtained from GFS, the available observational data within four hours from model initialization time has been assimilated into the model using Cressman successive correction scheme of objective analysis technique. This assigns a circular radius of influence and gives weightage to the observation based on the distance of the observation from gridpoint and corrects the first guess field in subsequent passes. Simulations have been carried out with and without objective analysis technique in order to verify the impact on the model predictions. The surface observations are taken from ISRO Auto Weather Stations (AWS), which are more than 500 in number. Profiles of pressure, temperature, dew point temperature, wind speed and wind direction are taken from the radiosonde/rawinsonde data provided by University of Wyoming. In addition to

Table 1. Brief description of MM5 model configuration.

\begin{tabular}{ll}
\hline Model & PSU/NCAR Meso Scale model MM5 \\
Map projection & Mercator \\
Domain & $45-106^{\circ} \mathrm{E} ; 10^{\circ} \mathrm{S}-38^{\circ} \mathrm{N}$ \\
Resolution & $27 \mathrm{~km}, 9 \mathrm{~km}$ (for convective activity) \\
No. of vertical levels & $23 \sigma$ levels \\
Horizontal grid & Arakawa $\mathrm{C}$ grid \\
Time integration & Leapfrog scheme $(\Delta t=81 \mathrm{~s})$ \\
Radiation scheme & RRTM \\
PBL scheme & MRF \\
Cumulus & Betts Miller \\
Micro physics & Dhudia Simple Ice
\end{tabular}


above observations, atmospheric motion wind vectors, i.e., water vapour winds and cloud motion wind vectors derived from Kalpana-1 satellite have been used for objective analysis.

\section{System description and results}

\subsection{Cyclonic storms}

The model simulations are carried out with and without objective analysis technique to check the impact in predicting the intensity and movement of cyclone. For this, a statistical evaluation is carried out in terms of root mean square error (RMSE) and percentage of improvement (POI). This is carried out based on model predicted maximum surface winds and IMD estimated maximum sustained surface wind. The model-predicted cyclone track is compared with the India Meteorological Department (IMD) best track, which gives track based on climatology, persistence, satellite technique, statistical technique and analogue technique. The vector displacement error (VDE) in predicting the track of cyclones is calculated for next $48 \mathrm{hr}$ with an interval of $12 \mathrm{hr}$. Analysis of the vertical structure of the three cyclones is carried out to observe the steering current. The spatial pattern of precipitation simulated by the model is compared with the observed rainfall from Tropical Rainfall Measuring Mission (TRMM). The rainfall measured from TRMM is the merged analysis of TRMM Microwave Imager (TMI), Precipitation Radar (PR) and rainguage observations carried out by NASA (http://disc2.nascom.nasa.gov/Giovanni/tovas/). The model-predicted maximum surface winds during these three cyclones are verified with the estimated winds provided by IMD, based on a 3min averaging technique. The detailed description of each system (source: IMD RSMC 2008 report) along with the corresponding model predictions is presented below.

\subsubsection{Rashmi}

System description: A low-pressure area formed over the west central BOB off Andhra coast on 24th and concentrated into a depression, lay centered at $0300 \mathrm{UTC}$ on 25 th near $16.5^{\circ} \mathrm{N}$ and $86.5^{\circ} \mathrm{E}$. System further moved to north north-east direction, intensified into a cyclonic storm (Rashmi) with maximum sustaining wind speeds of $17.5 \mathrm{~m} / \mathrm{s}$ in northwest sector of the system. Cyclone Rashmi lay centered at 1200 UTC on 26th in northwest BOB near $19.5^{\circ} \mathrm{N}$ and $88.0^{\circ} \mathrm{E}$. The system further moved in northeast direction, lay centered over north $\mathrm{BOB}$ near $21.5^{\circ} \mathrm{N}$ and $89.5^{\circ} \mathrm{E}$ with sustaining maximum wind speed of about $23 \mathrm{~m} / \mathrm{s}$. Finally the system crossed Bangladesh coast near $21.8^{\circ} \mathrm{N}$ and $89.5^{\circ} \mathrm{E}$
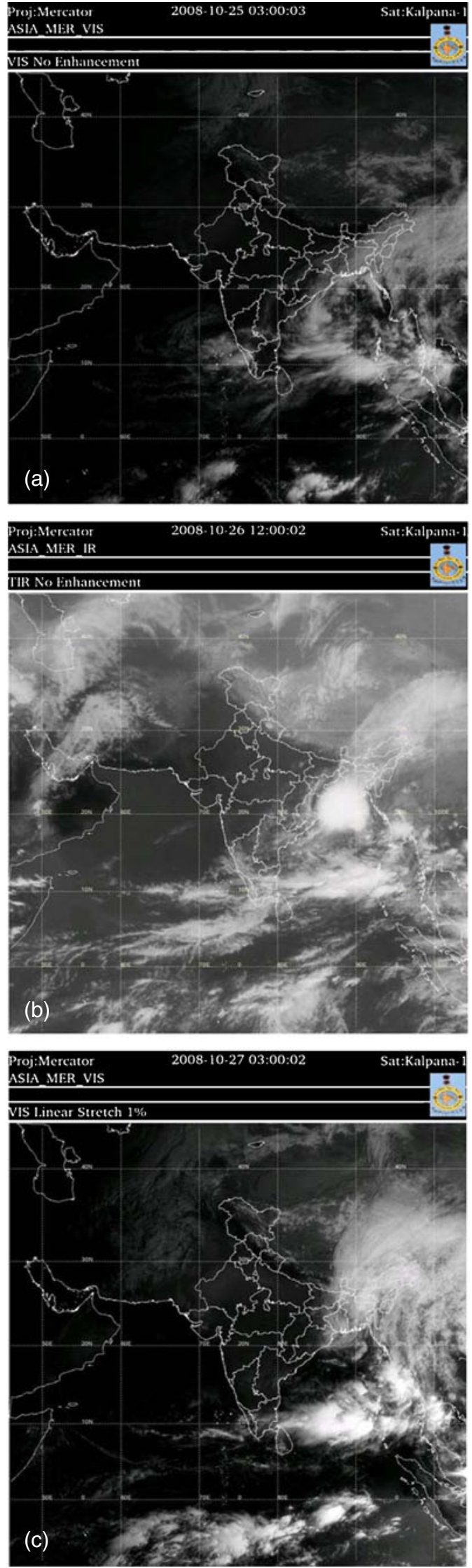

Figure 1. Kalpana-1 imageries of the system Rashmi on (a) 25th 0300 UTC, (b) 26th 1200 UTC, and (c) 27th 0300 UTC. 
around 2230 UTC of 26 th and then weakened into a deep depression. It further weakened to a well marked low by 27th 0900 UTC. The estimated lowest pressure of this cyclone as reported by IMD is $984.5 \mathrm{mb}$ on 26th at 21 UTC. It caused loss of life and property in Bangladesh and northeastern states of India due to heavy rainfall and squally winds. The satellite imageries of cyclone Rashmi during formative, matured and dissipative stages are shown in figure $1(\mathrm{a}, \mathrm{b}, \mathrm{c})$.

Model predictions: The model analysis on 25th 00 UTC showed a pressure drop of 5 hpa at the centre $\left(85.9^{\circ} \mathrm{E}\right.$ and $\left.18.29^{\circ} \mathrm{N}\right)$. The $24 \mathrm{hr}$ prediction (figure 2a) and $48 \mathrm{hr}$ prediction based on 25th 00 UTC IC showed a pressure drop of $6 \mathrm{hpa}$ and $10 \mathrm{hpa}$, respectively. The prediction of circulation at 850 hpa level (figure 2b), showed movement of the cyclone in the northeast direction. Model predictions based on 25th 12 UTC, 26th 00 UTC and 12 UTC IC indicated maximum pressure drop at 18 UTC of 26th against the IMD observed maximum pressure drop at 21 UTC of 26 th. The maximum pressure drop indicated with the above IC is 7,10 and 10 hpa respectively which is near to the observed maximum drop of $10 \mathrm{hpa}$. The predictions based on the four IC indicated the least central pressure of $994 \mathrm{hpa}$ at 18 UTC on 26th against the IMD observed least central pressure of $984 \mathrm{hpa}$ at 21 UTC of $26 \mathrm{th}$. The movement of the cyclone based on the four IC showed a northeast movement. On analysis of the vertical structure of the cyclone, the circulation was found extended up to $300 \mathrm{hpa}$ level and winds above this level moved northeastward which might have acted as steering current (figure 2c). The track predicted by the model based on 25th 00 UTC IC did not indicate landfall within next 48 hours. However, the predictions based on rest of the IC indicated at Head Bay with an error of 94, 11 and $25 \mathrm{~km}$, respectively. All the four simulations indicated the landfall between 26th 18 UTC and 27th 00 UTC, which is in agreement with the observed landfall at 2230 UTC of 26th. The positive impact of objective analysis in predicting the track of the cyclone with less error was clearly seen in predictions based on 25th 12 UTC IC (figure 3).

All the four simulations predicted the maximum surface winds of intensity $25-30 \mathrm{~m} / \mathrm{s}$ between 15 and 18 UTC of 26th against the observed at 21 UTC with an intensity of $23 \mathrm{~m} / \mathrm{s}$. Predictions based on 25th 00 UTC IC showed maximum intensity in the eastern sector of the cyclone on 26th 00 UTC and in southern sector on 27th 00 UTC (figure 4). These predictions in comparison with model analysis showed similar activity. The $24 \mathrm{hr}$ and $48 \mathrm{hr}$ predictions of rainfall (figure 5) based on 25th $00 \mathrm{UTC}$, 12 UTC and 26th 00 UTC IC showed maximum
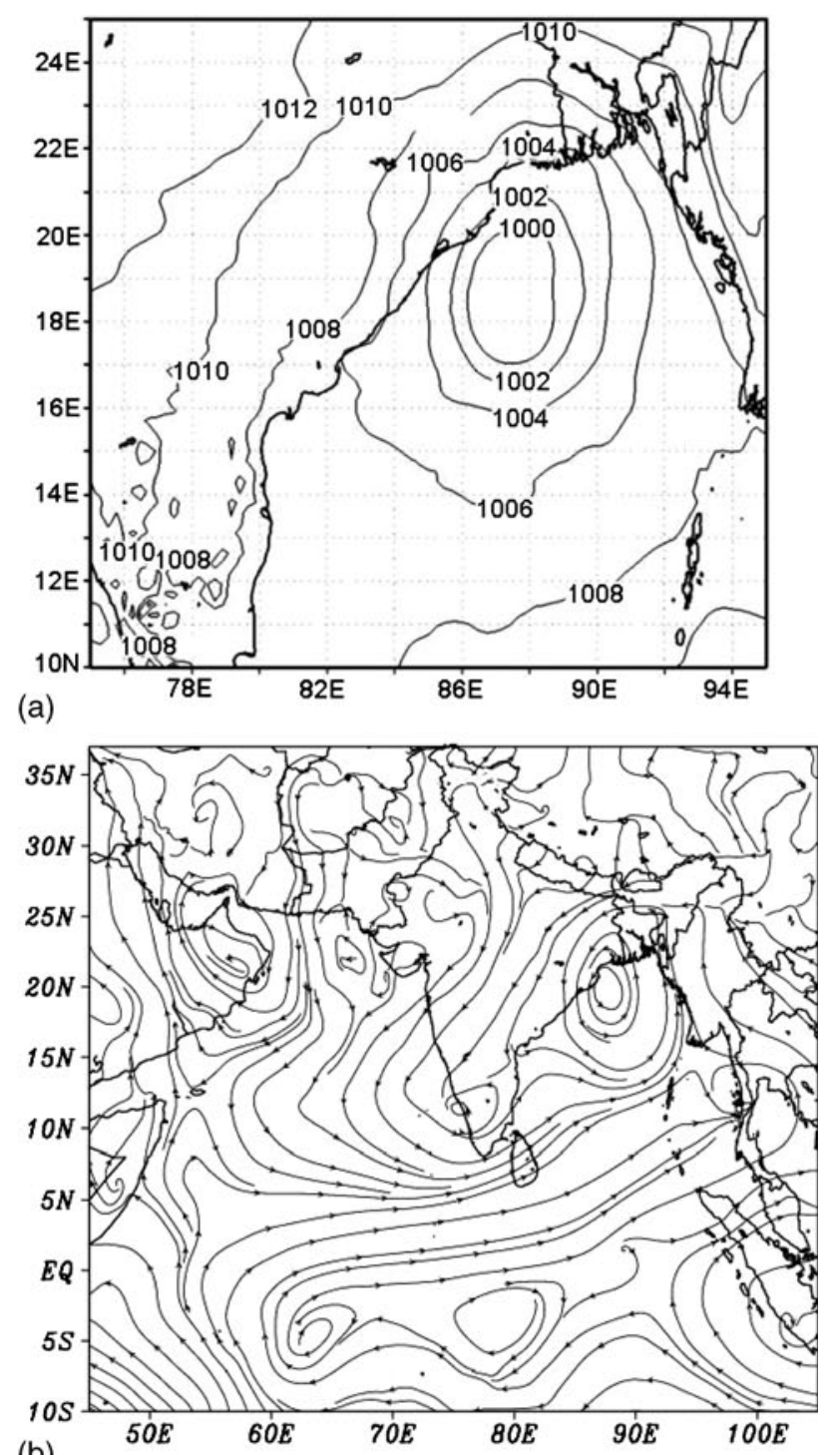

(b)

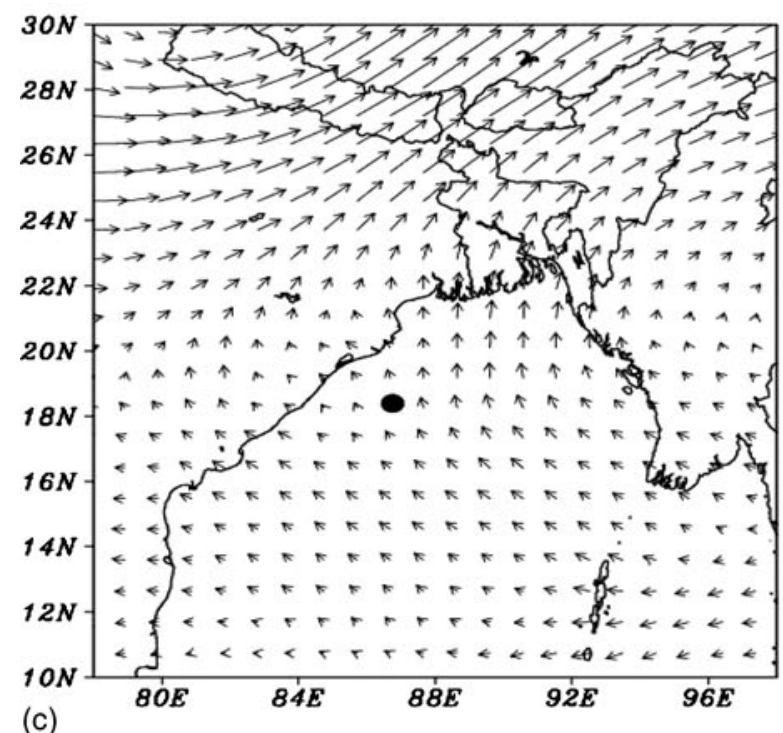

Figure 2. (a) Mean sea level pressure, (b) 850 hpa circulation, and (c) 200 hpa wind pattern with black dot indicating centre of the cyclone at $850 \mathrm{hpa}$, on 26th October 200800 UTC. 


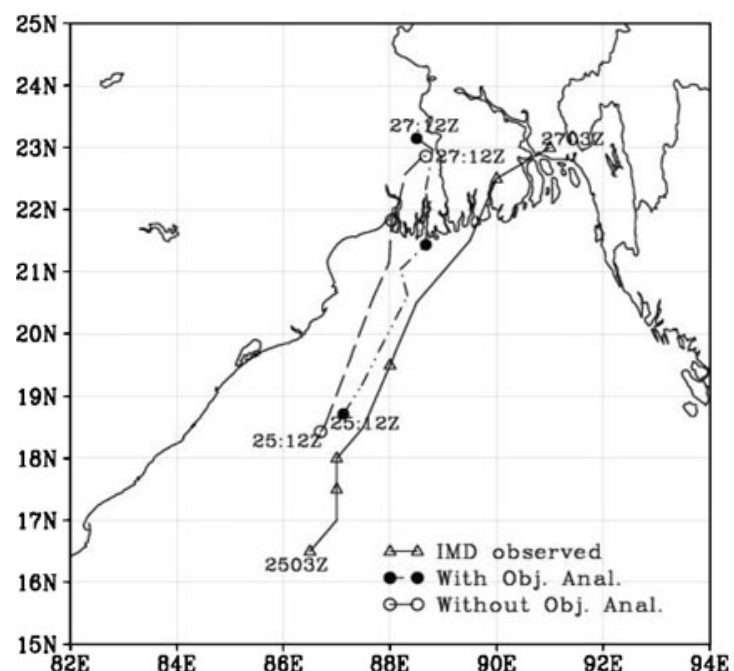

(a)

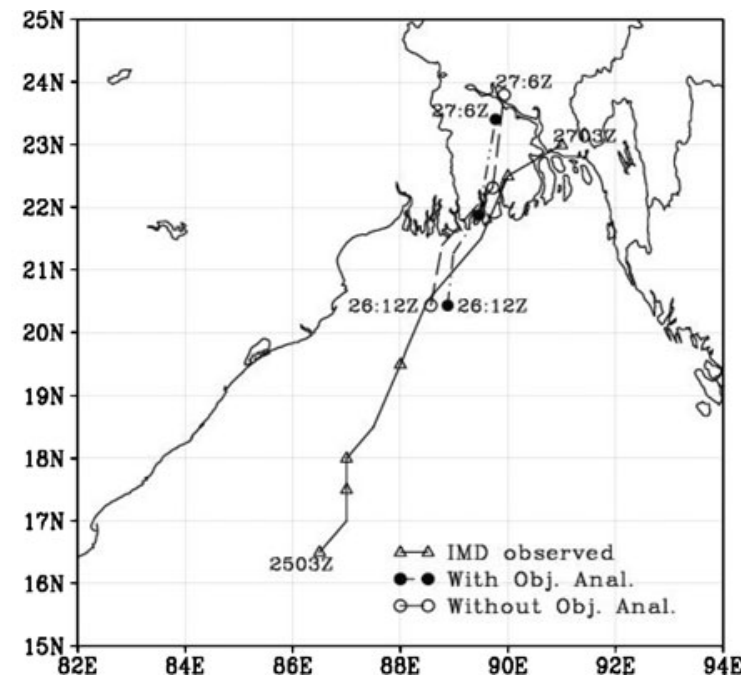

(b)

Figure 3. Comparison of predicted and IMD observed cyclone track of Rashmi based on (a) 25th 12 UTC, and (b) 26th 12 UTC IC.
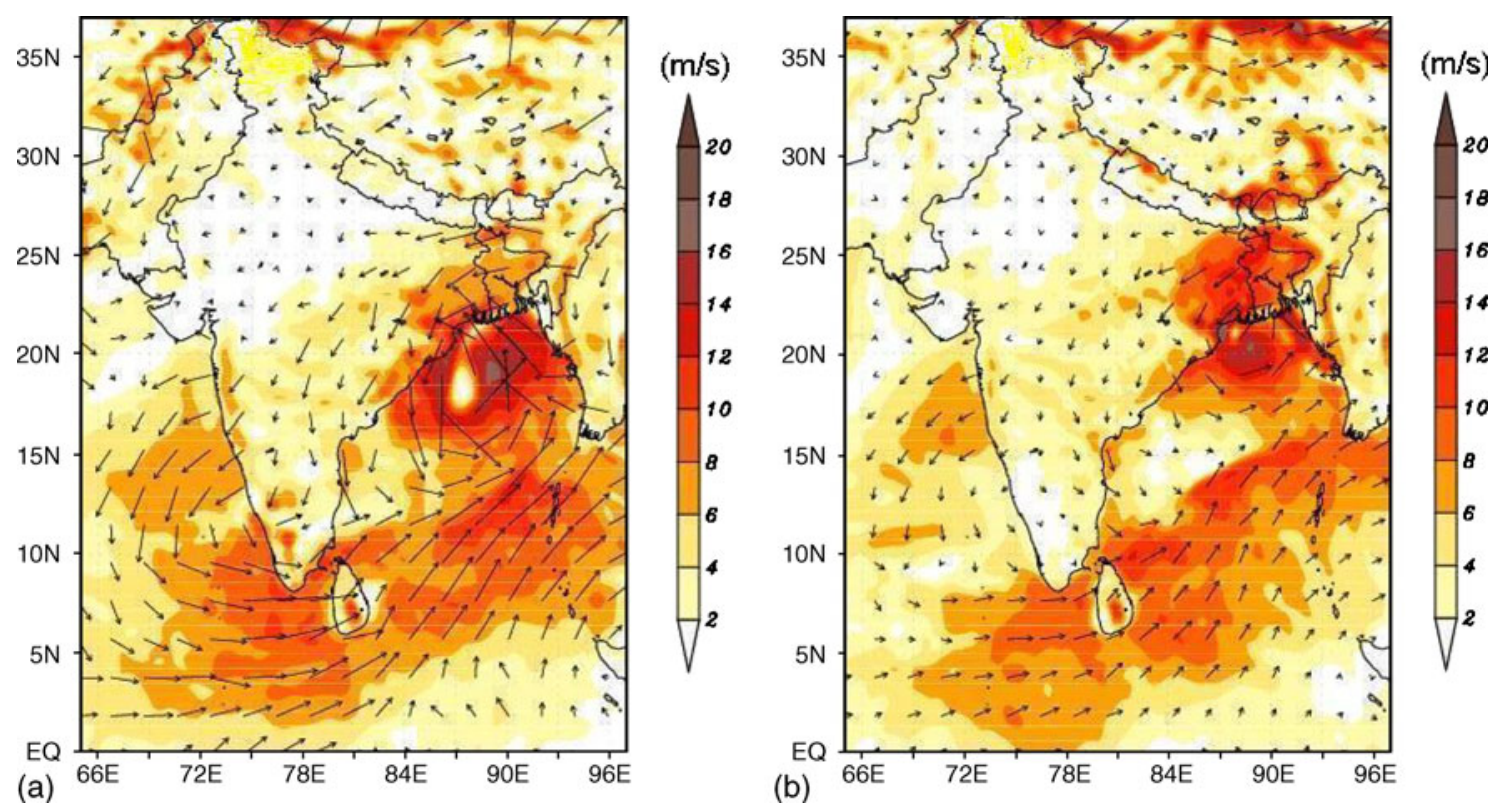

Figure 4. Surface winds predicted by the model based on 25th 00 UTC IC for (a) 26 th 00 UTC and (b) 27 th 00 UTC.

rainfall in the northern sector of the cyclone against the TRMM observed in southwest sector. Simulation based on 26th 12 UTC IC underestimated the amount of precipitation.

\subsubsection{Khai-Muk}

System description: A low-pressure area formed over central BOB (lat. $12.1^{\circ} \mathrm{N}$ and lon. $85.2^{\circ} \mathrm{E}$ ) and adjoining areas on 12th November. At 12 UTC of 13th this low-pressure concentrated into a depression over southwest BOB and lay centered near $11.5^{\circ} \mathrm{N}$ and $85.5^{\circ} \mathrm{E}$ at about $600 \mathrm{~km}$ southeast of Chennai. This depression moved in northnorthwest direction, intensified into a deep depression and lay centered at 03 UTC of 14th near $12.5^{\circ} \mathrm{N}$ and $85.0^{\circ} \mathrm{E}$. The system then moved in the northwest direction, intensified into a cyclonic storm (Khai-Muk) and lay centered at 12 UTC of 14 th over west central BOB near $14.0^{\circ} \mathrm{N}$ and $84.0^{\circ} \mathrm{E}$. The cyclone maintained its intensity while moving in west-northwest direction till 03 UTC of 15 th. The system weakened into a deep depression at 06 UTC of 15 th and lay centered at $14.5^{\circ} \mathrm{N}$ and $82.5^{\circ} \mathrm{E}$. The deep depression moved in 

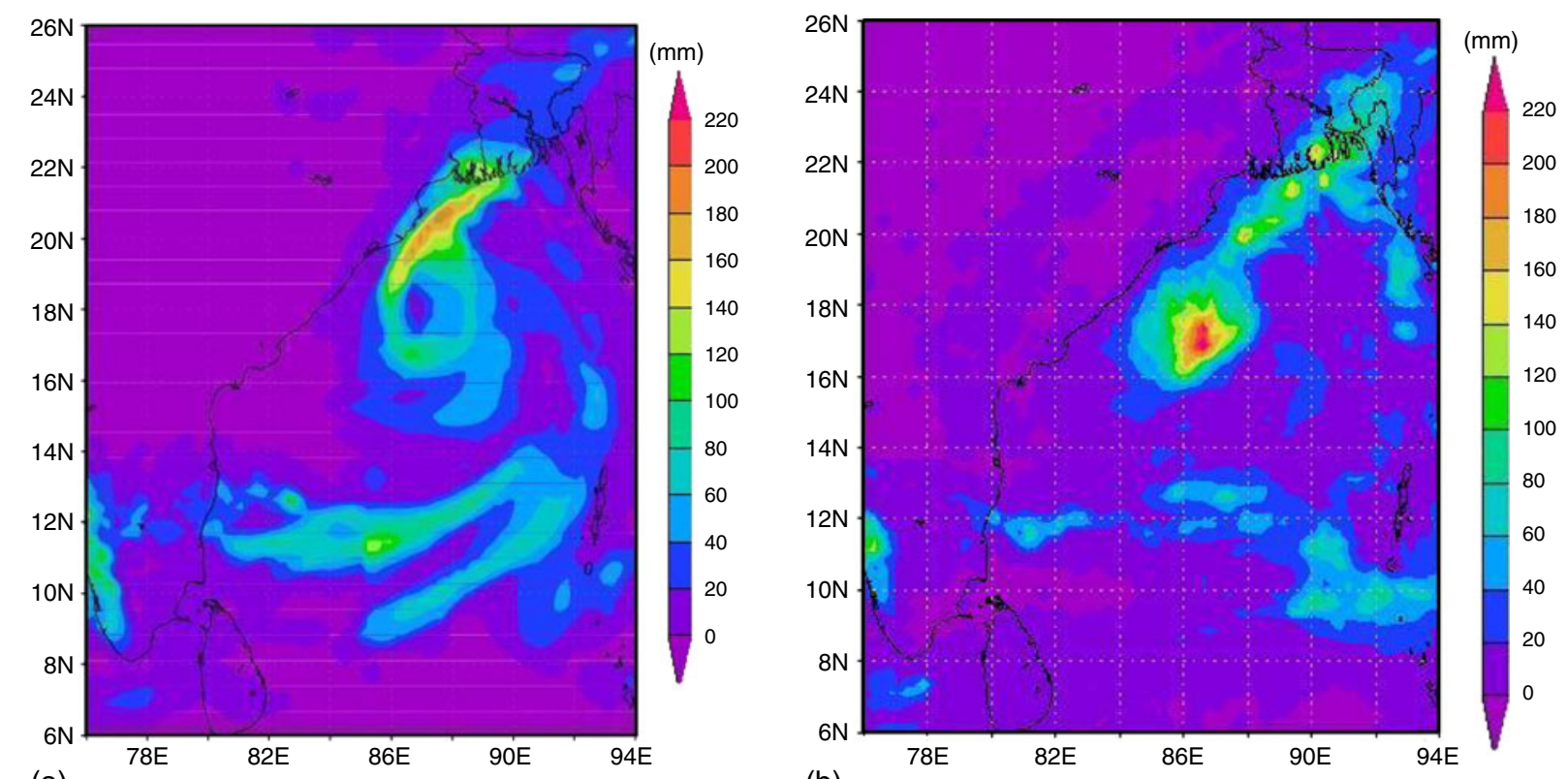

(a)

(b)
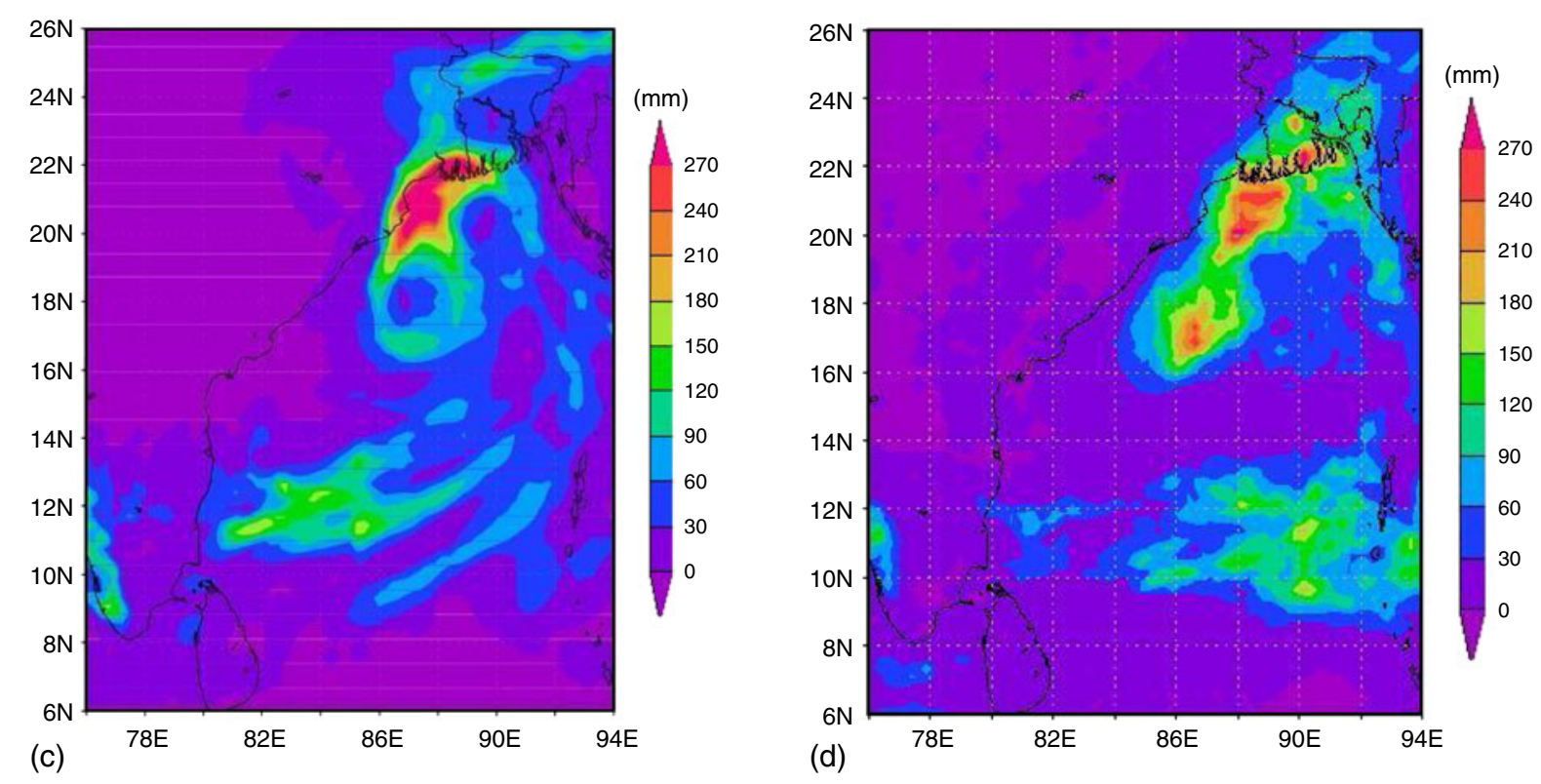

Figure 5. $24 \mathrm{hr}$ and $48 \mathrm{hr}$ accumulated rainfall predicted by MM5 based on 25th (a, c) 00 UTC IC and the corresponding TRMM observed rainfall $(\mathbf{b}, \mathbf{d})$.

west-northwest direction and crossed over south coastal Andhra Pradesh near Kavali $\left(14.9^{\circ} \mathrm{N}\right.$ and $79.9^{\circ} \mathrm{E}$ ) between 22 and 23 UTC of 15 th. Then it weakened into a depression and lay centered at 03 UTC of 16 th over Rayalseema. This further weakened into a well-marked low pressure over Raylseema and adjoining Telangana and interior Karnataka at 0900 UTC of 16th. The estimated lowest pressure of this cyclone as reported by IMD is 994 hpa on 14th 2100 UTC. The satellite imageries of this cyclone are shown in figure 6 .

Model predictions: Model analysis on 14th 00 UTC showed a pressure drop of $4 \mathrm{hpa}$ at the centre $\left(84.5^{\circ} \mathrm{E}\right.$ and $\left.12.4^{\circ} \mathrm{N}\right)$ in southwest BOB (figure 7a, b). Predictions based on 14th 12 UTC and 15th 00 UTC ICs showed a maximum pressure drop of $10 \mathrm{hpa}$ and $4 \mathrm{hpa}$ on 15 th 00 UTC and 12 UTC, respectively. A minimum central pressure of 998 hpa was predicted on 15th from 00-12 UTC, based on predictions of 14th 00 UTC IC against the observed $994 \mathrm{hpa}$ on 15th 00 UTC. Similar to the case of Rashmi, this system also had circulation up to about $300 \mathrm{hpa}$, and the flow above acted as steering current (figure 7c). The track of the cyclone predicted by MM5 based on 14th and 15th, 12 UTC IC (figure 8) indicated the landfall 

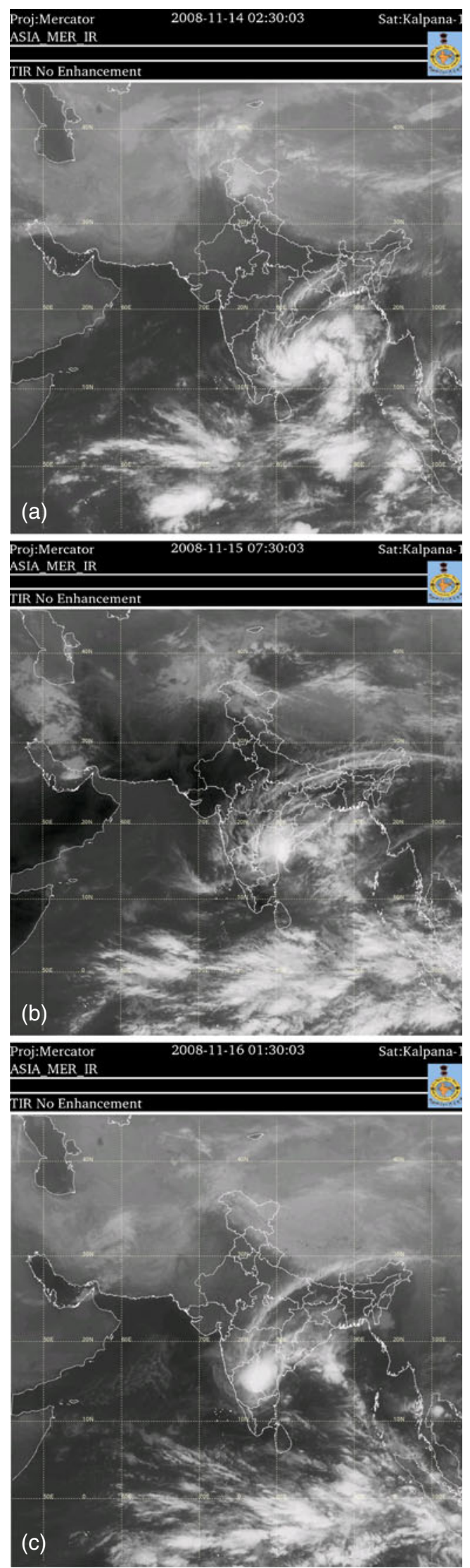

Figure 6. Kalpana-1 imageries of the system Khai-Muk on (a) 14th 0230 UTC, (b) 15th 0730 UTC, and (c) 16th 0130 UTC.
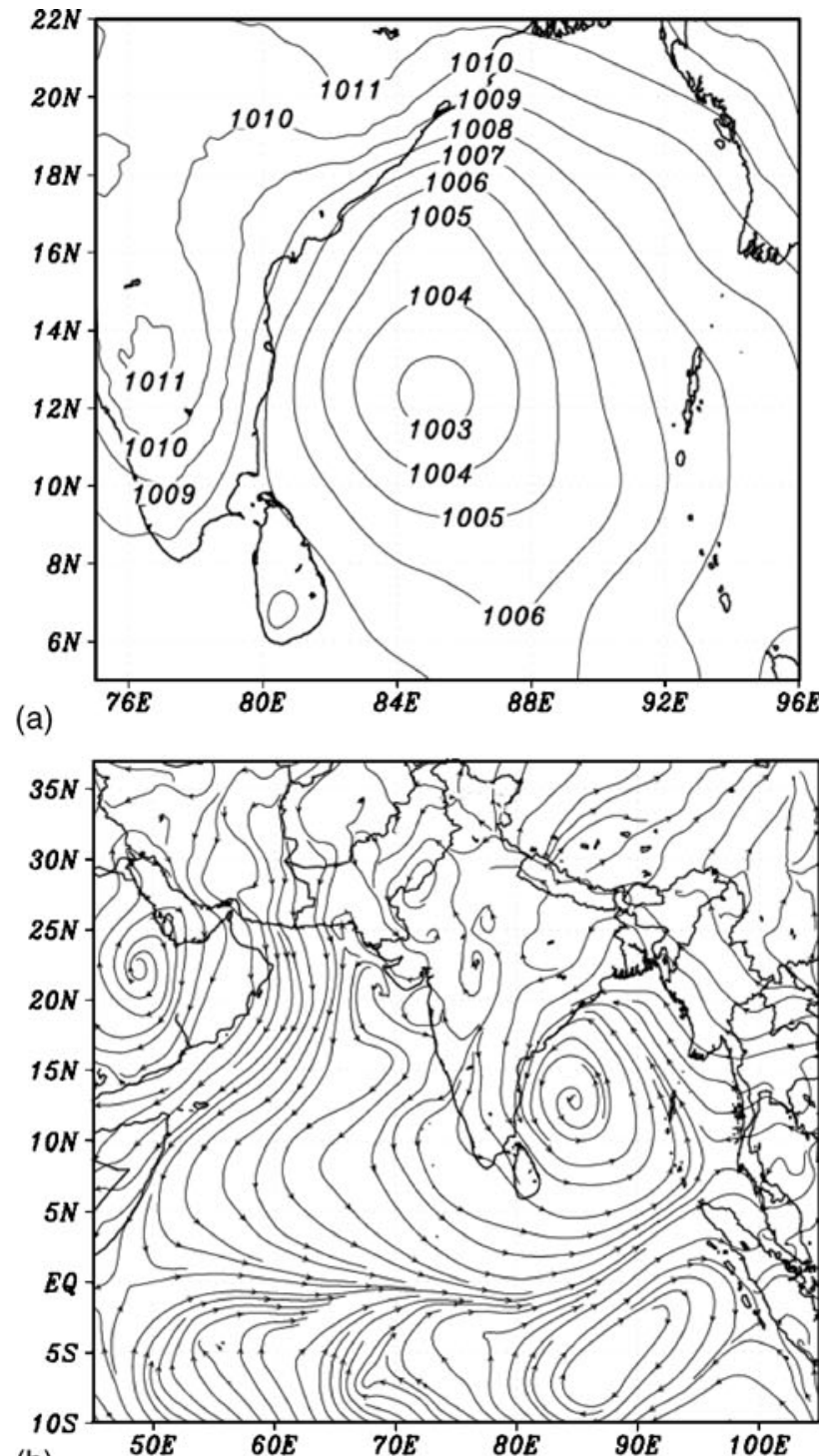

(b)

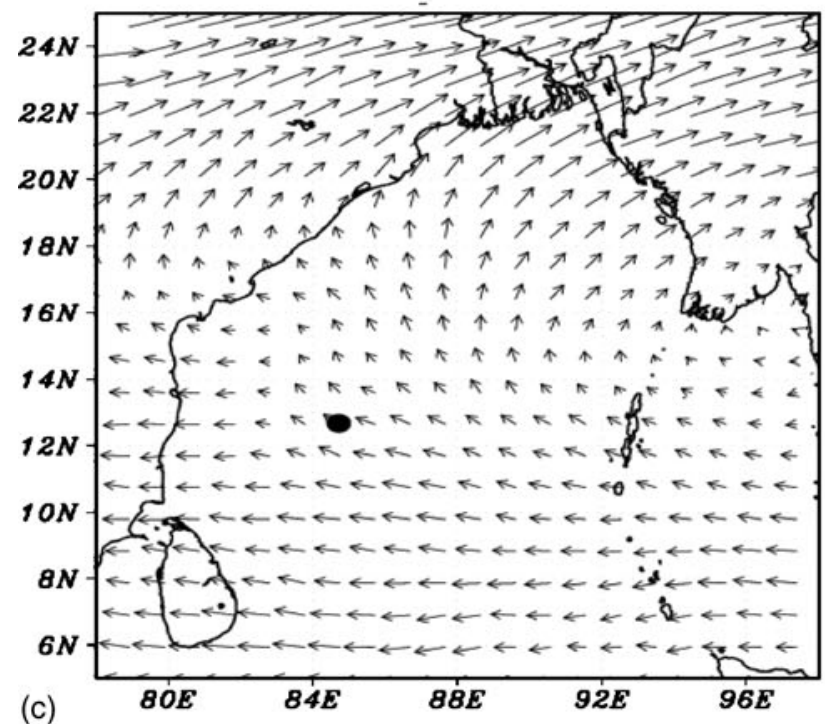

Figure 7. (a) Mean sea level pressure, (b) 850 hpa circulation, and (c) 200 hpa wind pattern with black dot indicating centre of the cyclone at $850 \mathrm{hpa}$, on 14th November 00 UTC. 
with an error of $165 \mathrm{~km}$ and $161 \mathrm{~km}$ each. Simulations based on 14th 00 UTC showed a time lag in predicting the movement of the cyclone with no landfall in 48 hours. However, an increase in vertical wind shear (850 hpa to $200 \mathrm{hpa}$ ) from 1025 knots was predicted by 15 th, 12 UTC. This might have restricted further intensification of the system, which was in correlation with the observation. This weakening of the system into deep depression before landfall was also predicted by the model based on 14th, 12 UTC IC with maximum prevailing surface winds of intensity $17 \mathrm{~m} / \mathrm{s}$ with a lead time of 30 hours. All the four simulations showed that the track predicted by the model with objective data analysis had less error when compared to that of without objective data analysis.

The maximum sustained winds predicted by the model with 14 th 00 UTC IC are in the range 28 $30 \mathrm{~m} / \mathrm{s}$ on 15 th between 00 and 12 UTC against the observed maximum winds of $20 \mathrm{~m} / \mathrm{s}$ on 15 th at 00 UTC. The $24 \mathrm{hr}$ and $48 \mathrm{hr}$ predictions (figure 9) based on all the IC showed the maximum prevailing wind in the northern sector, which was in agreement with the IMD observed winds. These predictions in comparison with the model analysis also showed maximum activity in north and northwest sectors. The $24 \mathrm{hr}$ rainfall predictions based on 14th and 15th 00 UTC IC showed that

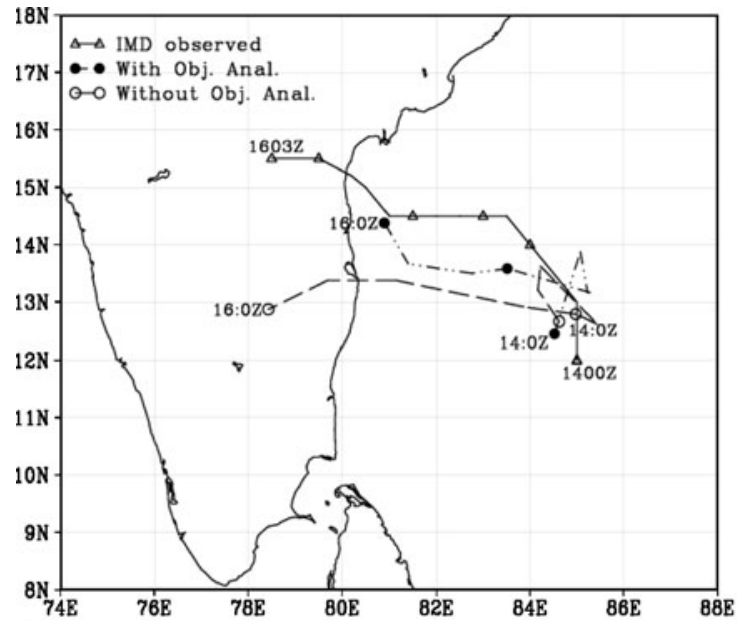

(a)

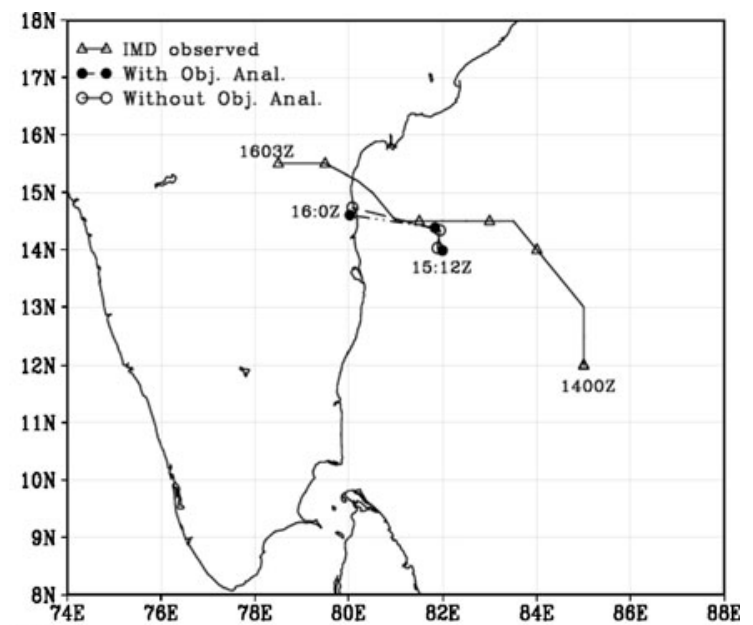

(b)

Figure 8. Comparison of predicted and IMD observed cyclone track of Khai-Muk based on (a) 14th 00 UTC, and (b) 15th 12 UTC IC.
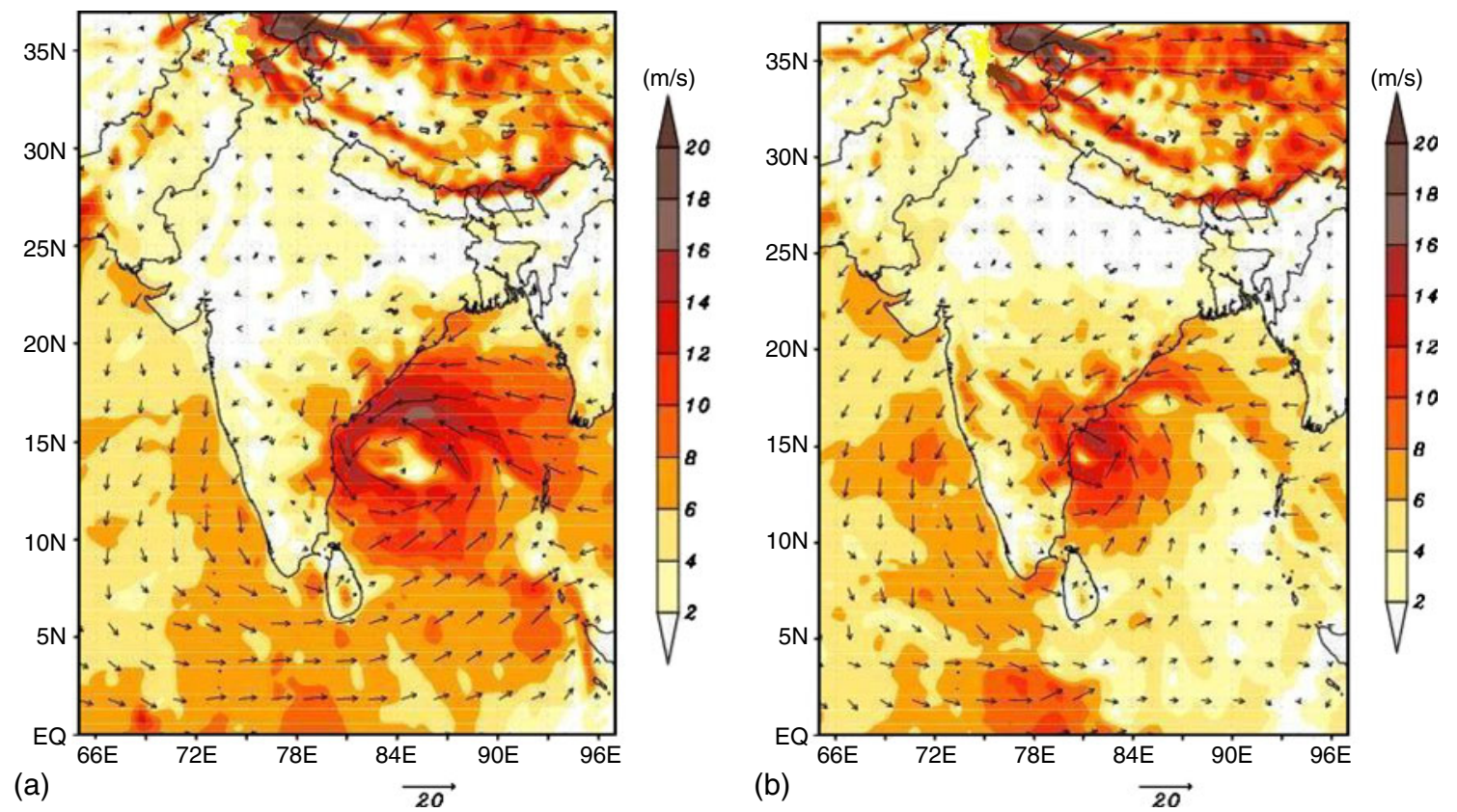

Figure 9. Surface winds predicted by the model based on 14th 00 UTC IC for (a) 15th 00 UTC, and (b) 16 th 00 UTC. 


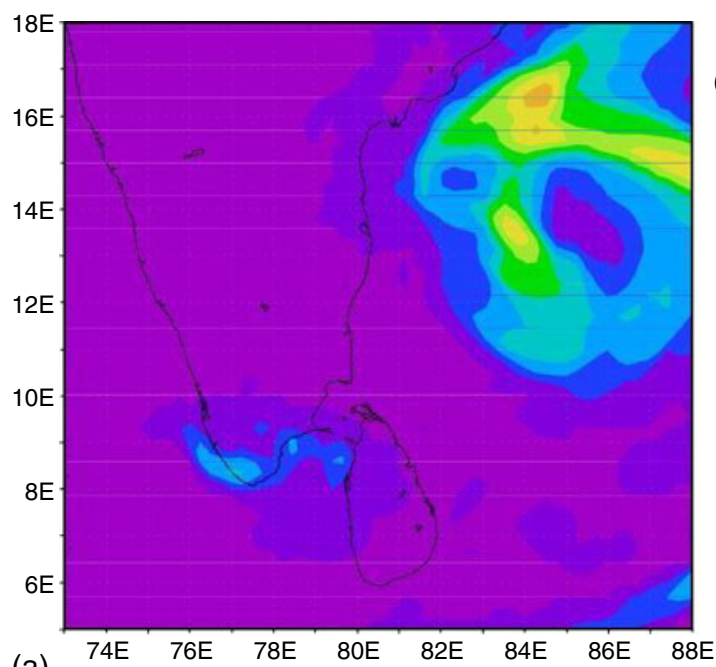

(a)

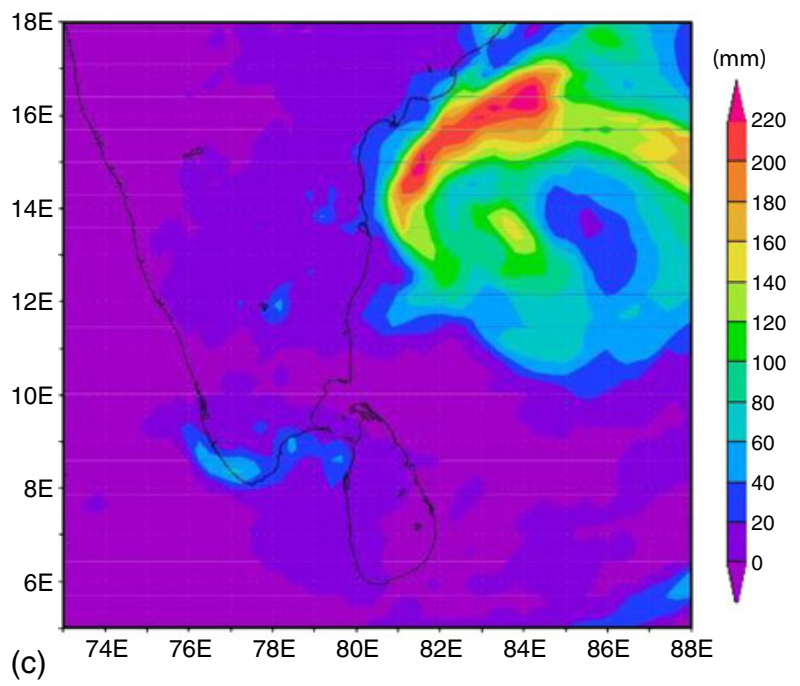

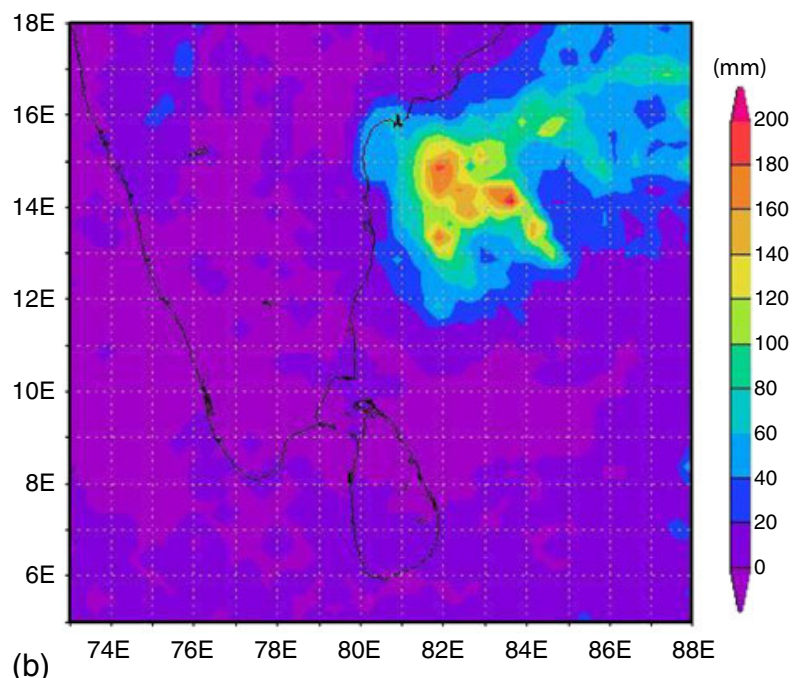

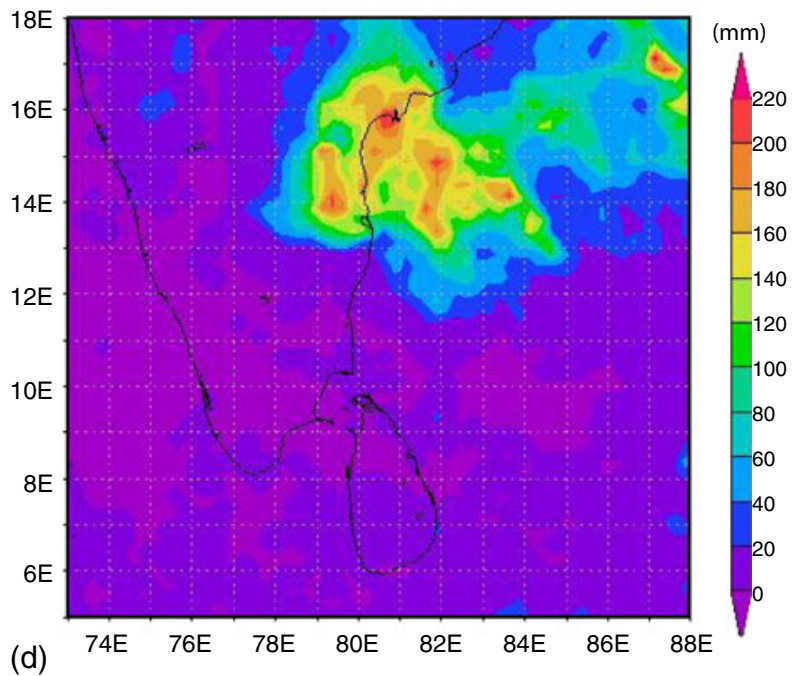

Figure 10. $24 \mathrm{hr}$ and $48 \mathrm{hr}$ accumulated rainfall predicted by MM5 based on 14th (a, c) 00 UTC IC and the corresponding TRMM observed rainfall $(\mathbf{b}, \mathbf{d})$.

the model has underestimated when compared to the TRMM observed rainfall (figure 10a, b). The $48 \mathrm{hr}$ predictions based on the above four simulations indicated maximum rainfall activity in the western sector matching with the TRMM observations (figure 10c, d).

\subsubsection{Nisha}

System description: A trough of low pressure laid over southwest BOB on 19th November. It moved to westcentral BOB off Sri Lanka, Tamil Nadu and south Andhra Pradesh coasts during 20th to 22nd. It then organized into a well-marked lowpressure area and further to a depression over north Sri Lanka. It intensified into a deep depression and lay centered over north Sri Lanka $\left(9^{\circ} \mathrm{N}, 81^{\circ} \mathrm{E}\right)$ at 12 UTC of 25 th. Further the system moved north-northwest and intensified into a cyclonic storm 'Nisha' over the southwest BOB and lay centered at $03 \mathrm{UTC}$ of 26 th near $10.5^{\circ} \mathrm{N}$ and $80.0^{\circ} \mathrm{E}$. As the system lay close to the coast, the system did not intensify further. It moved northward and lay centered at $00 \mathrm{UTC}$ of 27 th near $11.3^{\circ} \mathrm{N}$, $79.9^{\circ} \mathrm{E}$. The system crossed the Tamil Nadu coast north of Karikal near $11.3^{\circ} \mathrm{N}$ and $79.8^{\circ} \mathrm{E}$ between 00 and 01 UTC. Afterwards, the system moved in northwest direction and gradually weakened into a deep depression. It further weakened into a depression by 12 UTC of the same day and weakened into a well-marked low-pressure area at 00 UTC of 28th over north interior Tamil Nadu and adjoining areas of south interior Karnataka and Rayalseema. The estimated lowest pressure of this cyclone as reported by IMD is $996 \mathrm{hpa}$. The important feature of Nisha is that, the system remained quasi-stationary for about $24 \mathrm{hr}$ very close to the coast causing exceptionally very 

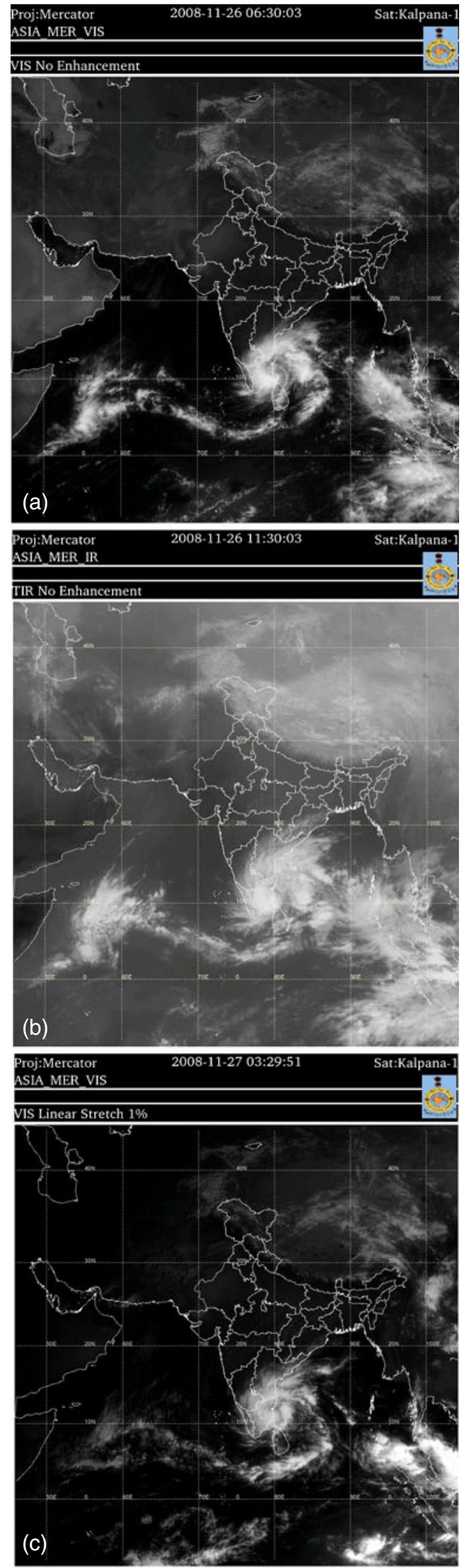

Figure 11. Kalpana-1 imageries of Nisha at (a) 26th 0630 UTC, (b) 26th 1130 UTC, and (c) 27th 0330 UTC.

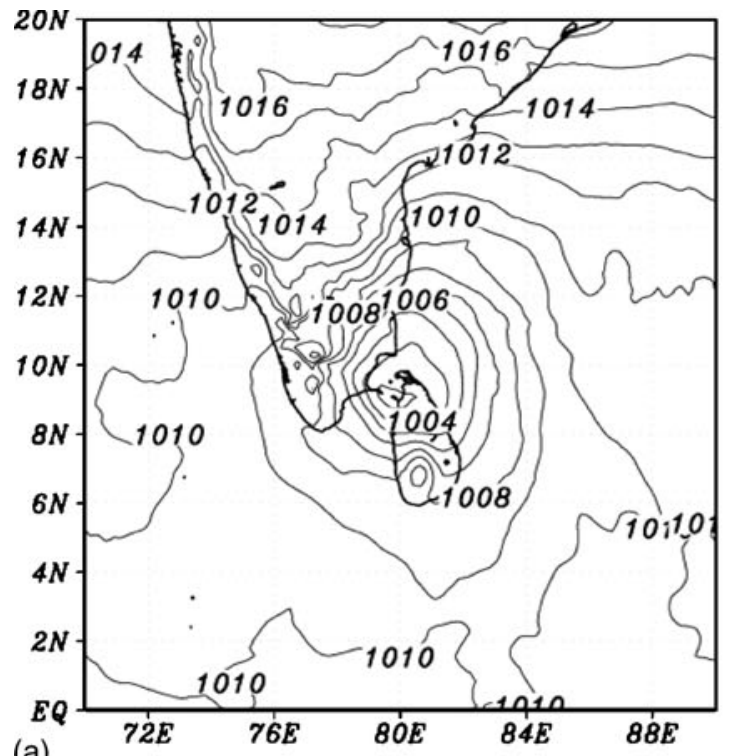

(a)

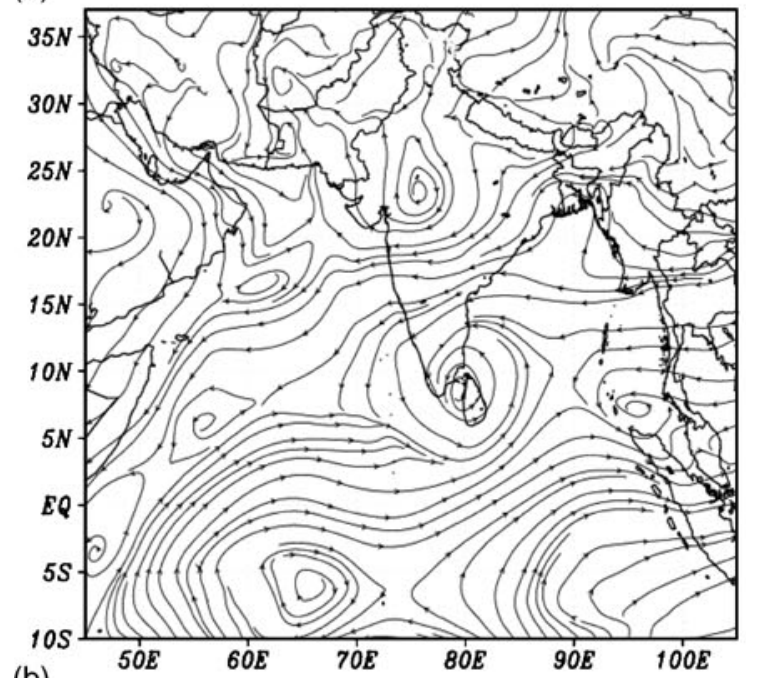

(b)

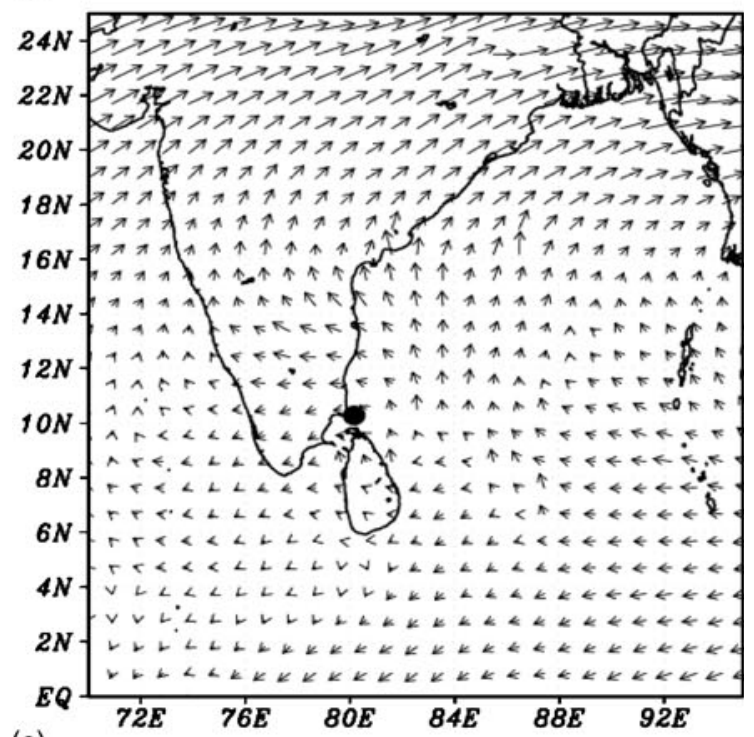

(c)

Figure 12. (a) Mean sea level pressure, (b) 850 hpa circulation, and (c) 200 hpa wind pattern with black dot indicating centre of the cyclone at $850 \mathrm{hpa}$, on 26th November 00 UTC. 
heavy rainfall over north Tamil Nadu and south Andhra coast. The satellite pictures at the formative stage, matured stage and dissipative stage of this cyclone are shown in figure $11(\mathrm{a}, \mathrm{b}, \mathrm{c})$ respectively.

Model predictions: The model analysis on 25th November 00 UTC IC showed a pressure drop of $3 \mathrm{hpa}$ at the centre in the southwest BOB to the north of Sri Lanka. The $24 \mathrm{hr}$ predictions on $25 \mathrm{th}$ 00 UTC IC indicated the intensification of cyclone with a pressure drop of $5 \mathrm{hpa}$ and the prediction of 850 hpa circulation showed a northward movement

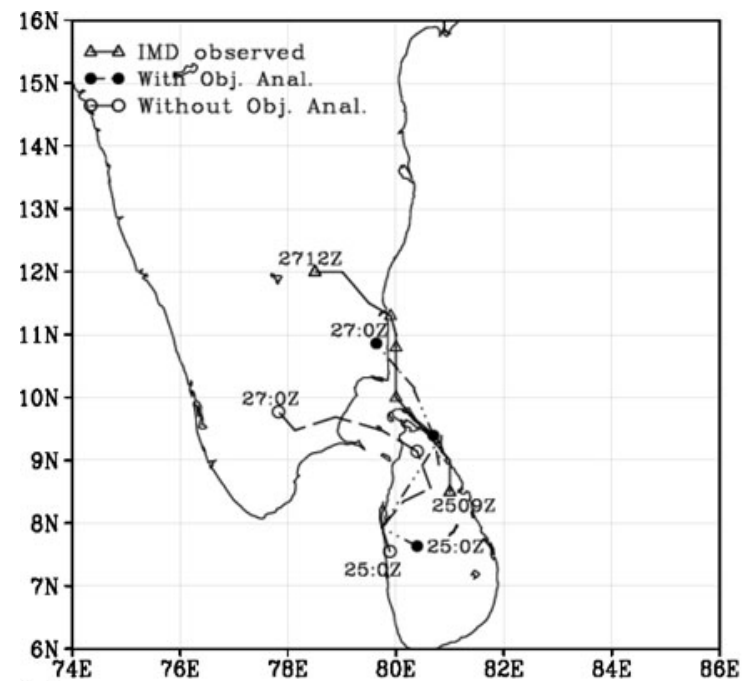

(a) of the cyclone by 26th 00 UTC (figure 12). The minimum central pressure predicted by the model with all four IC is 1000 hpa from 26th 12 UTC to 27th 00 UTC against the IMD observed of $996 \mathrm{hpa}$ from 26th 21 UTC to 27th 00 UTC. The track of the cyclone predicted based on 25th 00 UTC showed a northward movement in the next 48 hours (figure 13a). Predictions based on 26th 00 UTC showed an initial northward movement and then a westward movement in the next 48 hours. Analysis of the vertical structure of the system based on the above two IC showed that the circulation

Figure 13. Comparison of predicted and IMD observed cyclone track of Nisha based on (a) 25th 00 UTC, and (b) 27th 00 UTC IC.

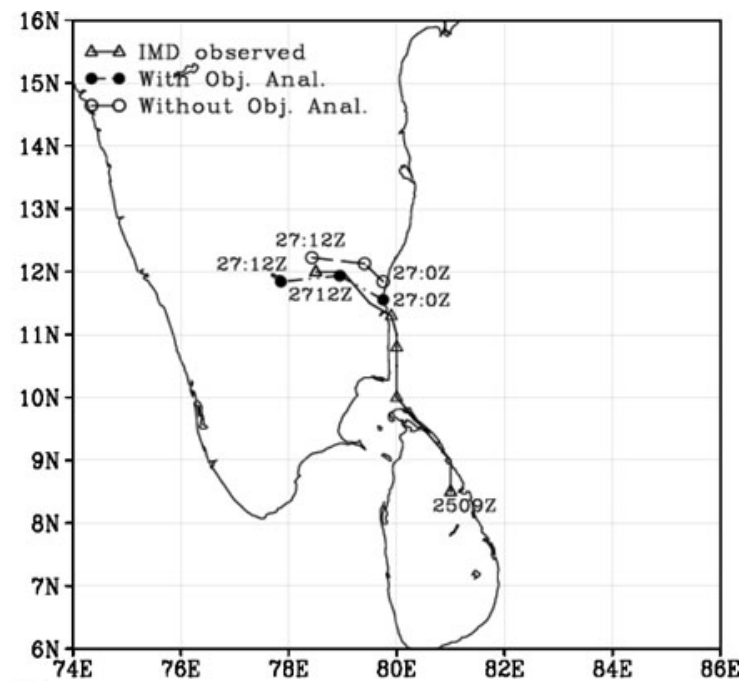

(b)
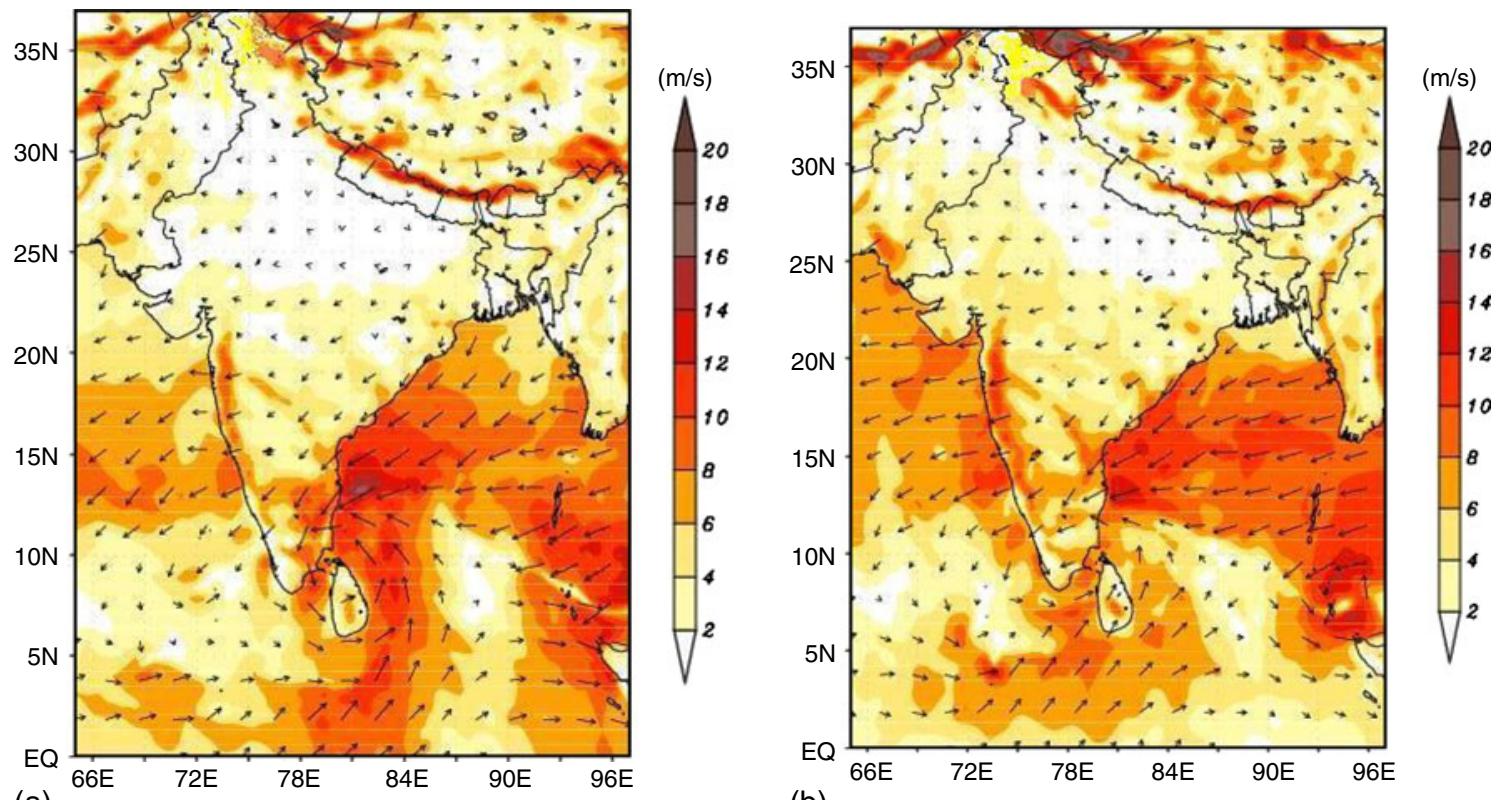

(b)

Figure 14. Surface winds as predicted by the model based on 25th 00 UTC IC for (a) 26th 00 UTC, and (b) 27th 00 UTC November. 

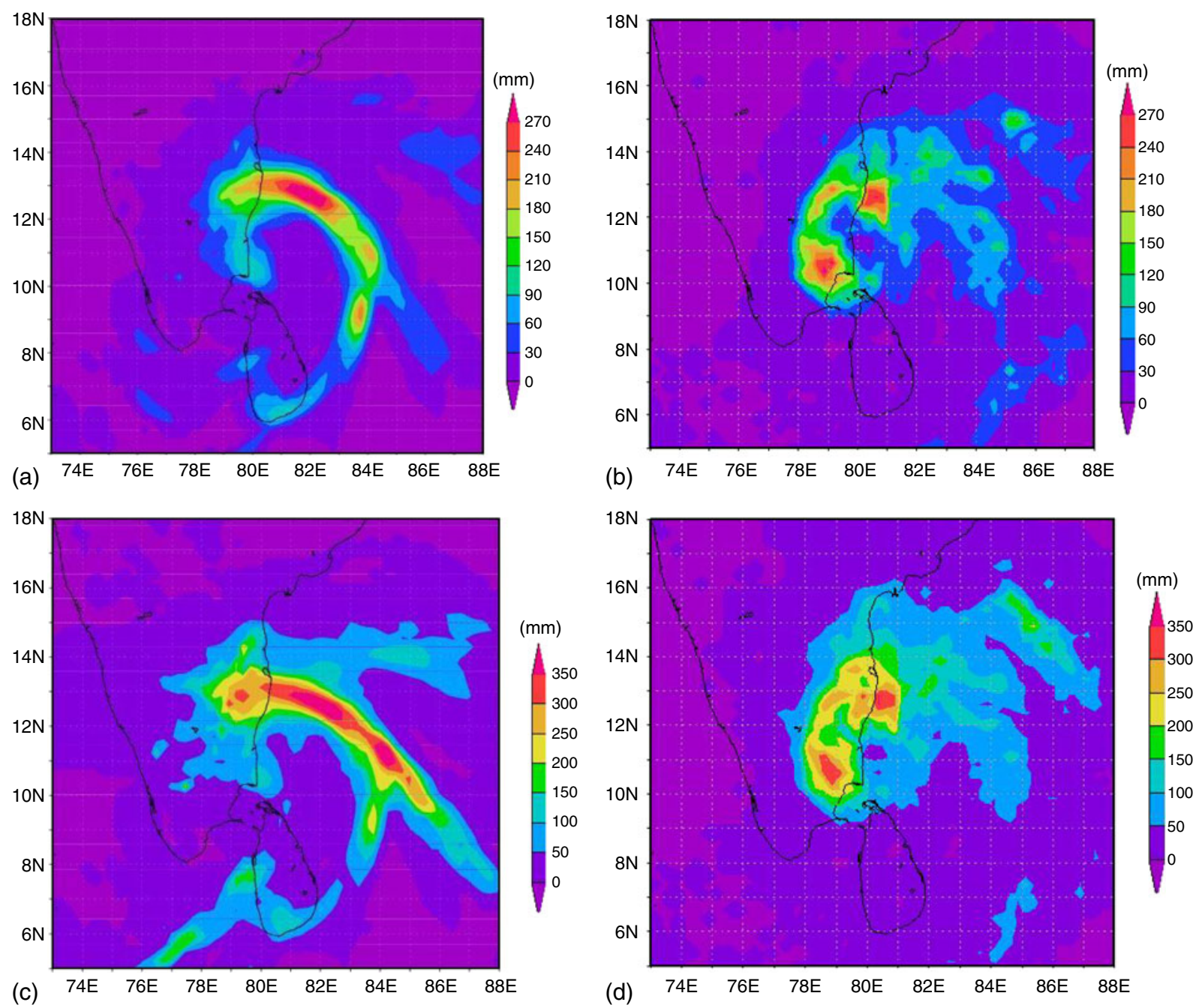

Figure 15. $24 \mathrm{hr}$ and $48 \mathrm{hr}$ accumulated rainfall predicted by MM5 based on 25th (a, c) 00 UTC IC and the corresponding TRMM observed rainfall $(\mathbf{b}, \mathbf{d})$.

extended up to 300 hpa level. So the winds above this level, which had a weak northeasterly flow (figure 12c), might have acted as steering current, leading to the quasi-stationary northward movement of the system, that is an important feature of this cyclone. Out of the four IC, predictions based on 25th 00 UTC indicated the landfall with an error of $77 \mathrm{~km}$ and predictions based on 26th 00 and 12 UTC indicated the landfall with an error of $44 \mathrm{~km}$. Predictions with 26th 00 UTC indicated westward movement of the system after landfall whereas it moved in the NW direction. The model predictions based on 27th 00 UTC IC (figure 13b) predicted the movement of the cyclone in the northwest direction after its landfall, which was in accordance with the IMD observed track. The impact of objective data analysis on the model predictions was well observed in predicting the track based on 25th 00 UTC IC. An error of $77 \mathrm{~km}$ was observed in predicting the landfall of the cyclone with objective analysis technique against an error of $218 \mathrm{~km}$ without objective data analysis. Similarly in all the other three simulations, difference in the VDE of the position of cyclone showed a positive impact.

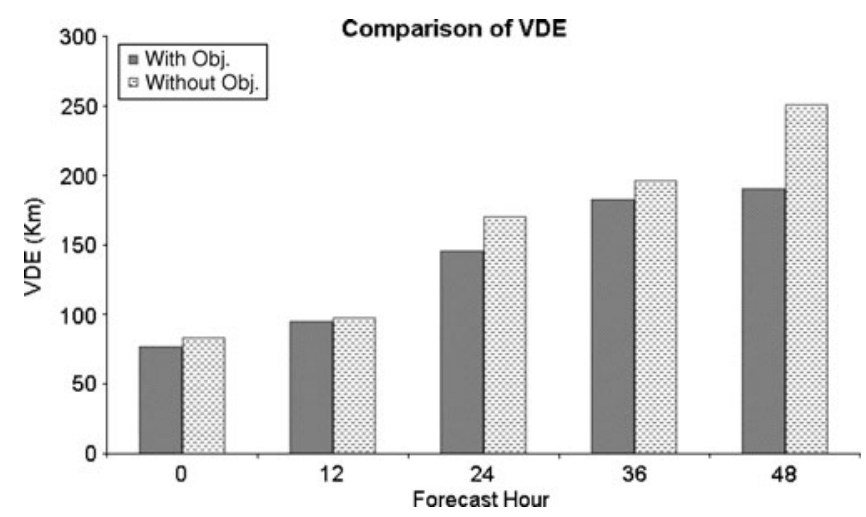

Figure 16. Comparison of mean vector displacement error with and without objective analysis. 

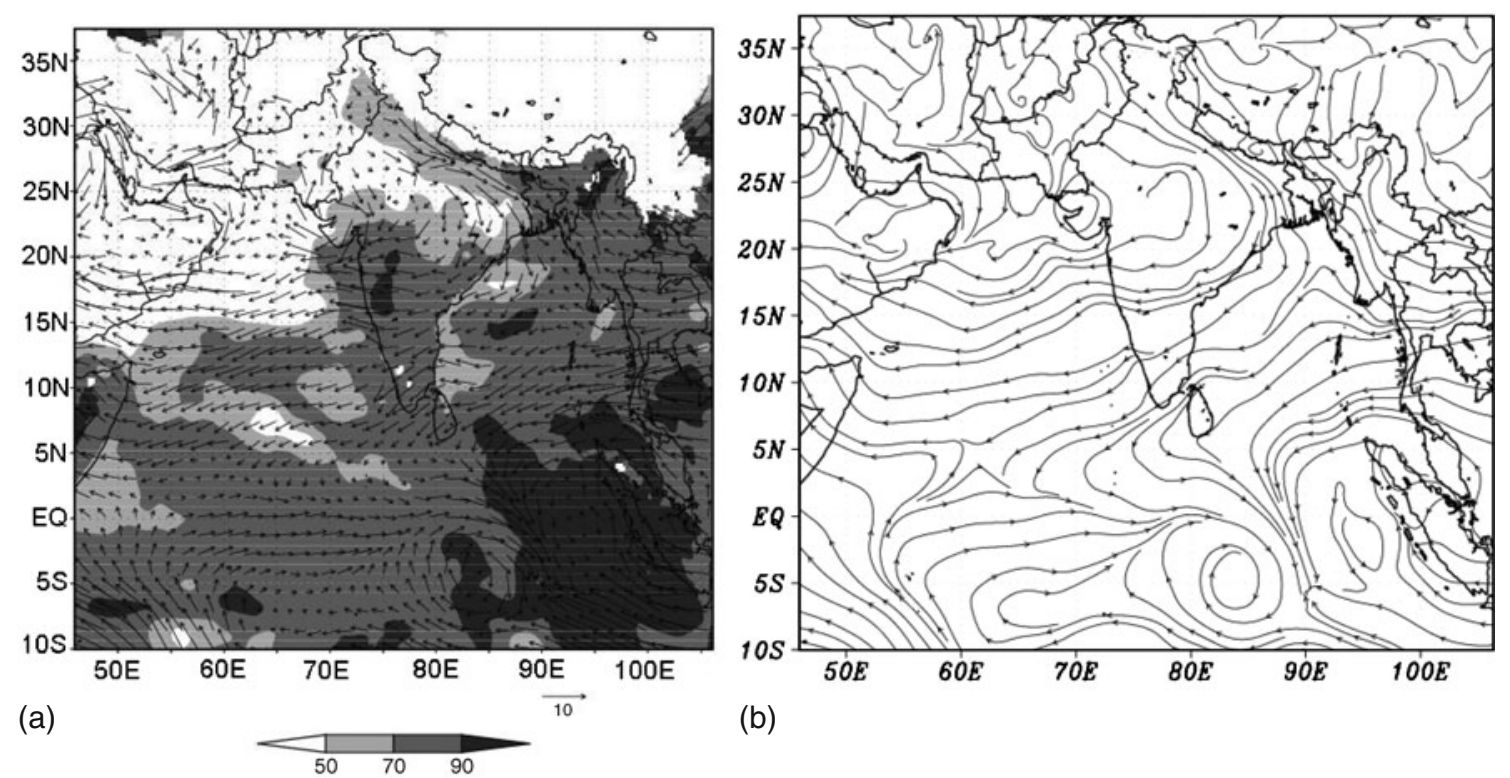

(b)
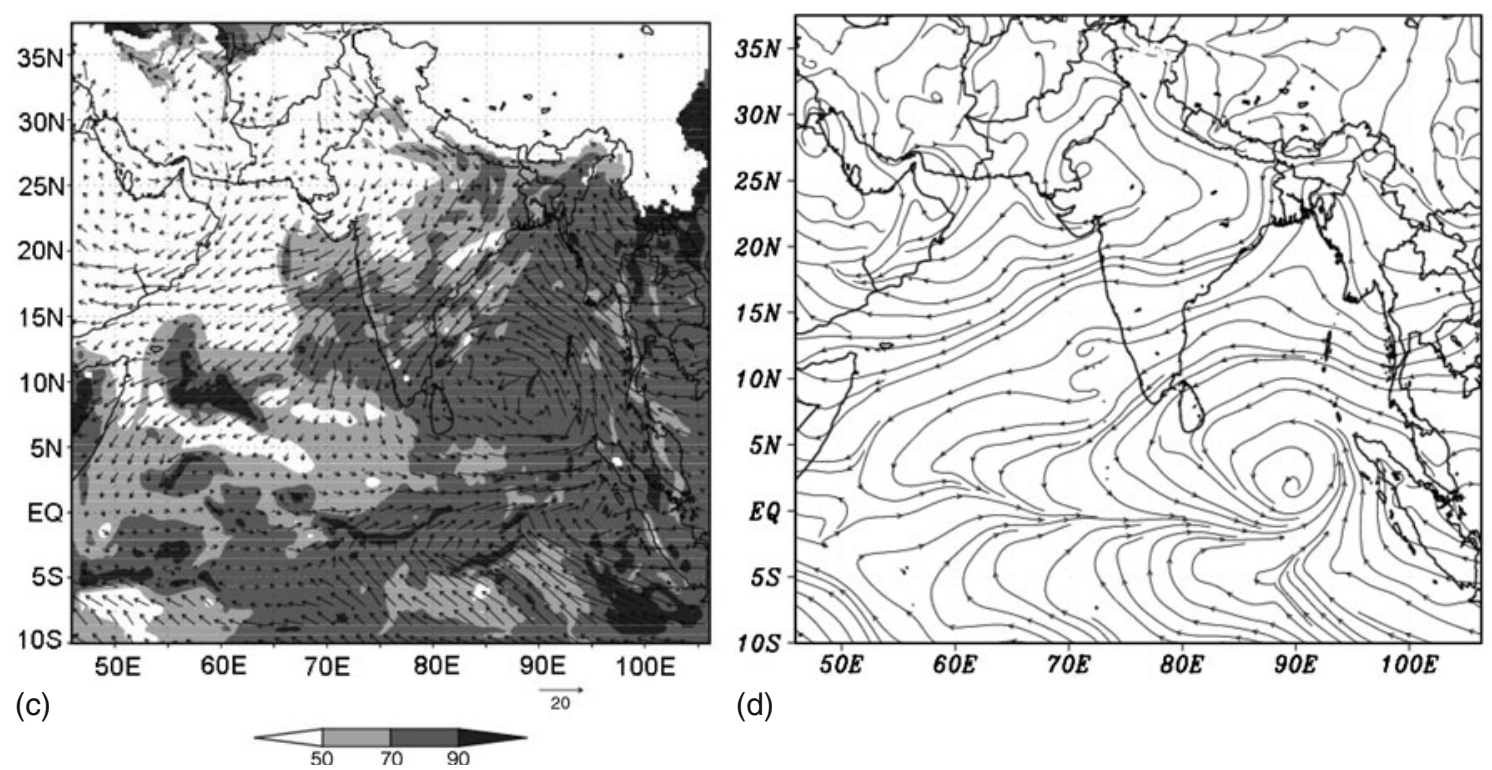

(d)

Figure 17. Relative humidity and circulation at 850 hpa on 10th (a, b) and 11th (c, d) 00 UTC based on 10 th 00 UTC IC.

In the case of Nisha, predictions made with all four IC were well in agreement with observations reported by IMD, i.e., peak winds of the order of 25 to $28 \mathrm{~m} / \mathrm{s}$ between 26th 12 UTC and 27 th 00 UTC. The $24 \mathrm{hr}$ forecast of surface wind indicates maximum intensity in northern sector of the cyclone (figure 14). Model analysis on 26th 00 UTC also showed a maximum intensity in northern sector as predicted. However, analysis on 27 th 00 UTC showed maximum intensity of surface winds in western sector of the cyclone. The spatial distribution of rainfall predicted by the model with all four IC showed maximum rainfall activity in the northern sector; whereas, TRMM observation showed maximum rainfall activity in the western sector (figure 15). Though the model could capture the intensity of the cyclone, the exact movement after landfall could not be well predicted in comparison with the other two cyclones. This may be due to the movement of the system over complex terrain in which relatively more frictional forces came into effect after its landfall.

\subsubsection{Statistical evaluation}

The positive impact of objective analysis of data as discussed in earlier sections is supported by a statistical evaluation carried out on model-predicted maximum surface winds in comparison with IMD 
estimated maximum sustained winds. RMSE is calculated for all the cases for the $48 \mathrm{hr}$ forecast with an interval of $12 \mathrm{hr}$. Based on RMSE, the POI in the model predictions with objective analysis over the predictions without objective analysis has been calculated. In the initial time step, there is no significant change observed. The POI observed in 12, 24, 36 and 48 hour forecast are $5.8 \%, 5.5 \%, 12 \%$ and $31 \%$, respectively. This shows that the POI of the simulations with objective analysis technique increases with model time integration.

The VDE at $12 \mathrm{hr}$ interval is calculated for all the simulations, based on the model predicted position, with and without objective analysis technique, to the IMD observed position. The mean VDE calculated for all the three cyclones for next 48 hours with $12 \mathrm{hr}$ interval is presented in figure 16. A mean initial positional error of $76 \mathrm{~km}$ is observed in locating the centre of the cyclone. We observe that this analysis error gets added with forecast time. For all the time steps the VDE calculated with objective analysis is less compared to the other. The track of the cyclone could be predicted 24 hours before with an error of 100-150 km and for $48 \mathrm{hr}$ with an error of approximately $200 \mathrm{~km}$.

\subsection{NE monsoon convective rainfall events}

The mean onset date of northeast monsoon over Sriharikota region is 20th October. But in 2008, the features of onset like the strong northeasterly flow and rainfall, were observed from 12th October. This feature originated from combined effect of an intense easterly wave over south BOB, presence of anti-cyclone over Rajasthan, upper air circulation over Arabian Sea off Kerala, northward shift of ITCZ (figure 17). These synoptic conditions triggered the northeasterly flow over central BOB. The intrusion of moist easterlies and northeasterlies from BOB, lead to an intense convective activity associated with moderate rain spells over Sriharikota region from 12 th to $22 \mathrm{nd}$ October 2008.

Model predictions for 24 hours, based on 00 UTC initial condition of the corresponding days of activity were considered for the analysis. Location specific products like vertical velocity, relative humidity and stability indices (Total Total index and $\mathrm{K}$ index) were found to be more informative in predicting the convective activity. Time height cross section of $\mathrm{RH}$ and vertical velocity predicted by the model in all the three cases showed a very good indication of convective activity (figure 18). Plots based on 12th and 16th October
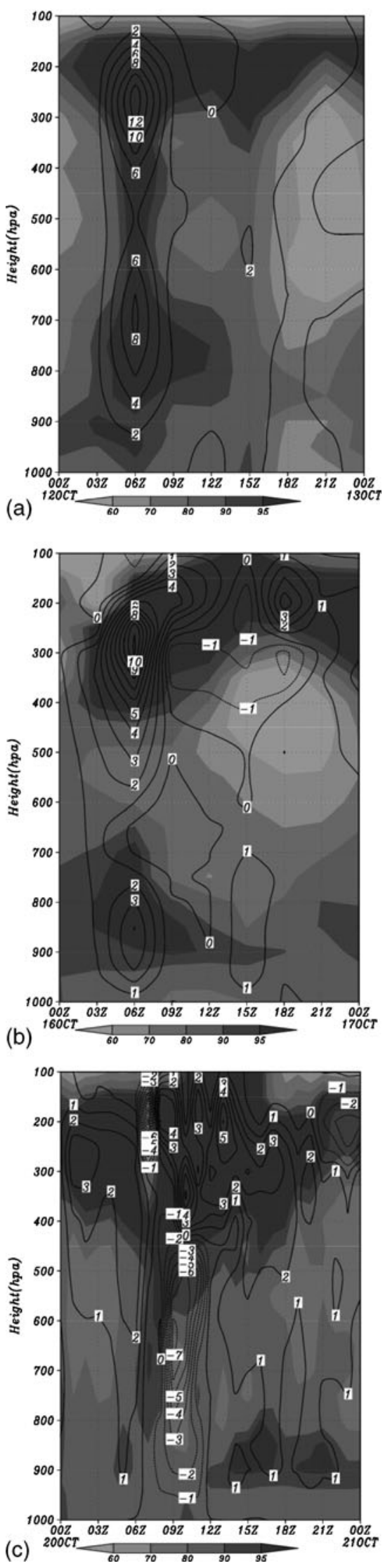

Figure 18. Time series plot of relative humidity and vertical velocity over SHAR region based on (a) 12th October 00 UTC, (b) 16th October 00 UTC, and (c) 20th October 00 UTC IC. 
Table 2. Predicted variation of stability indices (Total Total index and $K$ index) values for the three convective events.

\begin{tabular}{|c|c|c|c|c|c|c|}
\hline \multirow{2}{*}{$\begin{array}{l}\text { Date } \\
\text { Time (UTC) }\end{array}$} & \multicolumn{2}{|c|}{$12 / 10 / 2008$} & \multicolumn{2}{|c|}{$16 / 10 / 2008$} & \multicolumn{2}{|c|}{$20 / 10 / 2008$} \\
\hline & $\mathrm{TT}$ & $\mathrm{K}$ & $\mathrm{TT}$ & $\mathrm{K}$ & $\mathrm{TT}$ & K \\
\hline 00 & 42.62 & 33.34 & 44.64 & 37.77 & 43.75 & 38 \\
\hline 03 & 45.04 & 38.08 & 45.35 & 39.19 & 44.4 & 35.5 \\
\hline 06 & 48.97 & 40.71 & 45.14 & 40.11 & 40.5 & 31.5 \\
\hline 09 & 45.71 & 39.21 & 45.33 & 36.53 & 46.5 & 41 \\
\hline 12 & 45.32 & 39.16 & 43.79 & 34.67 & 44.5 & 37 \\
\hline 15 & 46.13 & 37.69 & 43.00 & 33.90 & 45.25 & 37.5 \\
\hline 18 & 43.58 & 32.51 & 44.17 & 35.22 & 44.75 & 37.75 \\
\hline 21 & 44.38 & 33.44 & 44.26 & 36.31 & 44.75 & 37 \\
\hline 24 & 43.49 & 35.37 & 44.88 & 37.76 & 42.75 & 35.3 \\
\hline
\end{tabular}
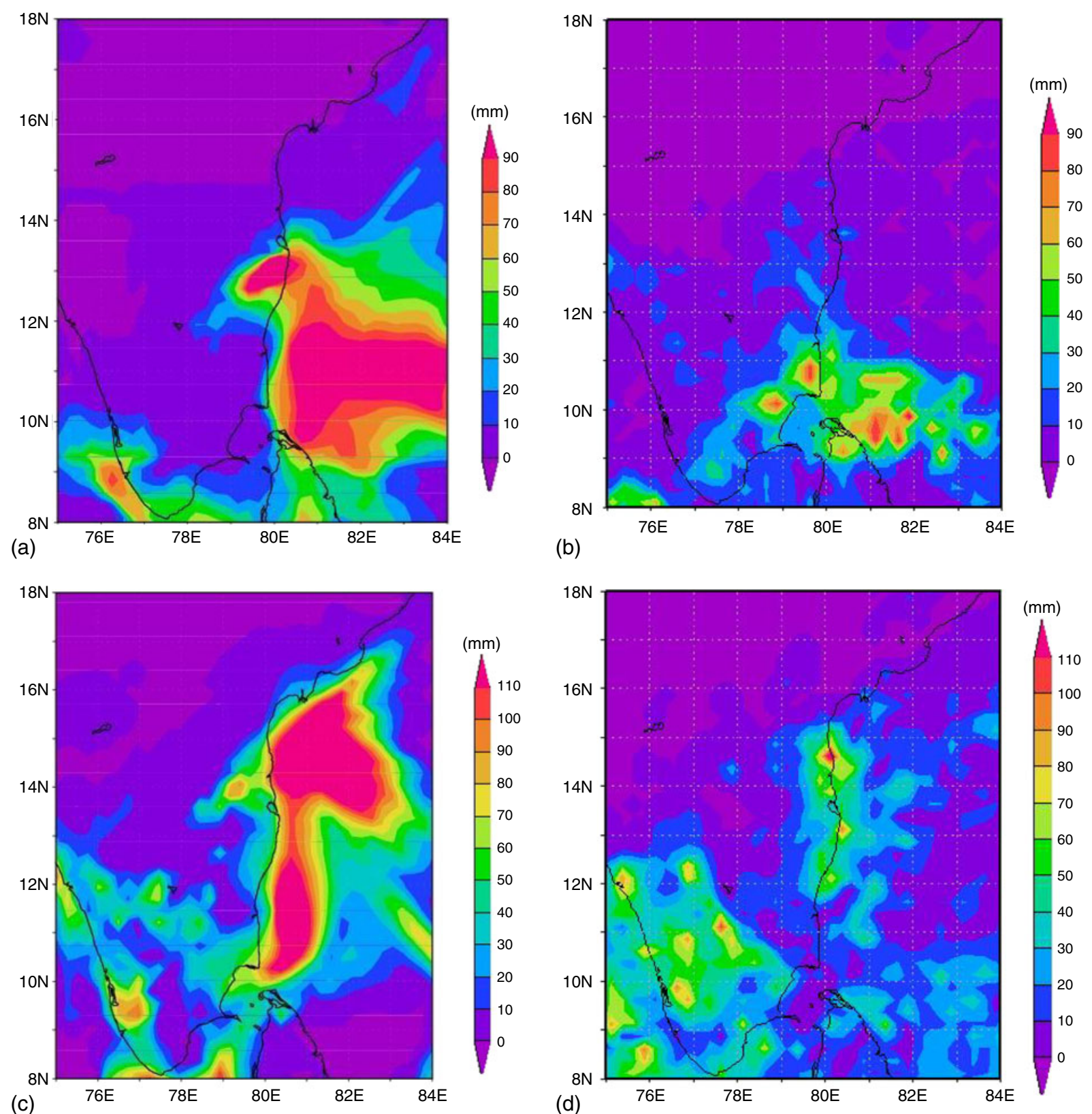

Figure 19. $24 \mathrm{hr}$ accumulated rain predicted by the model on (a) 12th and (c) 20th October and corresponding TRMM observed rain $(\mathbf{b}, \mathbf{d})$. 
00 UTC IC showed updrafts of intensity $12 \mathrm{~cm} / \mathrm{s}$ prevailing over SHAR region at 6 UTC, which was the observed time of activity. But on 20th, the thunderstorm occurred at 12 UTC against the prediction at 9 UTC. To predict probability of thunderstorm event, the atmospheric stability indices namely Total index and $\mathrm{K}$ index were also considered and presented in table 2. Predictions for three heavy rainfall events due to convective activity on 12th, 16th and 20th were also considered. The model predictions of rainfall intensity in comparison with TRMM observed showed that the model could well capture the activity on all the days, but has quantitatively overestimated (figure 19).

\section{Conclusions}

This study concludes that all the three cyclones during NE monsoon 2008 have been well tracked by MM5. The intensity predictions of the cyclones are also in good agreement with the observations. Analysis of vertical wind shear clearly indicates the weakening of the cyclonic storm Khai-Muk before landfall with a lead-time of about 30 hours. The quasi-stationary movement of the cyclone Nisha, which is the special feature of this cyclone, could be captured based on the vertical structure of the system along with the environmental flow. But the movement of the cyclone Nisha could not be predicted accurately after the landfall compared to other two cyclones. This may be attributed to the impact of frictional forces on the system due to the track on complex terrain. From the analysis carried out on vertical structure of these three cyclones and prevailing wind field, it is observed that the environmental flow above the level of maximum extent of circulation acts as steering current on which the track of the cyclone depends. From the POI, the advantage of objective analysis technique is clearly observed in the model predictions with an improvement of $31 \%$ for 48 -hr prediction. The mean VDE, calculated at every 12-hr interval indicates that the system could be well tracked after it attains deep depression stage. It may also be concluded that the track of system could be predicted 24 hours before with VDE of 100-150 km and $48 \mathrm{hr}$ before with an error of approximately $200 \mathrm{~km}$. This may be attributed to the initial positional error in fixing the centre of the cyclone. This error may be reduced by adopting the bogussing technique in fixing the centre of the cyclone, which will be carried out in future studies. The convective activity during the onset of northeast monsoon could also be well predicted based on vertical velocity and stability indices and used as crucial input for forecast during PSLV-C11/Chandrayan-1 launch campaign. Also the mean rainfall and heavy rainfall events due to convective activity were well predicted by MM5.

\section{Acknowledgements}

The authors are thankful to ISRO authorities for allowing them to carry out research under PRWONAM project. They thank NCEP for providing the real time global forecasting system data. The satellite derived winds provided by MOSDAC, SAC and the radiosonde data provided by University of Wyoming is also acknowledged. The authors also owe thanks to IMD for providing the observational datasets, INSAT imageries and the best track data. The precipitation estimates provided by NASA (TRMM) is gratefully acknowledged.

\section{References}

Betts A K and Miller M J 1986 A new convective adjustment scheme. Part II: Single column tests using GATE wave, BOMEX, ATEX and Arctic air-mass data sets; Quart. J. Roy. Meteor. Soc. 112 693-709.

Braun S A 2002 A cloud resolving model of hurricane BOB (1991) storm structure and eye wall buoyancy; Mon. Weather Rev. 130 1573-1592.

De Angelis D 1976 World of tropical cyclones - North Indian Ocean; Mar. Weather Log. 20 191-194.

Done J, Davis C A and Weisman M 2004 The next generation of NWP: Explicit forecasts of convection using the weather research and forecasting (WRF) model; Atmos. Sci. Lett. 5 110-117.

Gray W M 1975 Tropical cyclone genesis; Department of Atmospheric Sciences, Paper No 232, Colorado State University, Port Collins Co., USA, 121.

Grell G, Dhudia J and Stauffer D R 1995 A description of the fifth generation Penn State/NCAR mesoscale model (MM5); NCAR Tech. Note.

Jimy Dhudia 1989 Numerical study of convection observed during the winter monsoon experiment using a meso scale two-dimensional model; J. Atmos. Sci. 46 3077-3107.

Litta A J and Mohanty U C 2008 Simulation of a severe thunderstorm event during the field experiment of STORM programme 2006, using WRF-NMM model; Curr. Sci. 95 204-214.

Mandal M, Mohanty U C and Raman S 2004 A study on the impact of parameterization of physical processes on prediction of tropical cyclones over the Bay of Bengal with NCAR/PSU meso-scale model; Nat. Hazards 31 391-414.

Mlawer E J, Taubman S J, Brown P D, Iacano M J and Clough S A 1997 Radiative transfer for inhomogenous atmosphere: RRTM, a validate correlated-k model for the longwave; J. Geophys. Res. 102 16,663-16,682.

Mohanty U C, Mandal M and Raman S 2004 Simulation of Orissa Super Cyclone (1999) using PSU/NCAR mesoscale model; Nat. Hazards 31 373-390.

Patra K P, Santhanam M S, Potty K V J, Tiwari M and Rao P L S 2000 Simulation of tropical cyclones using regional weather prediction models; Curr. Sci. 79 70-78.

Pattnaik D R and Rama Rao Y V 2009 Track prediction of severe cyclone 'Nargis' using high resolution weather 
research forecasting (WRF) model; J. Earth Syst. Sci. $118309-329$.

Rao G V and Bhaskar Rao 2003 A review of some observed characteristics of tropical cyclones and preliminary numerical simulations of their kinematic features; Proc. Indian Nat. Sci. Acad. 69 523-541.
Weisman M L, Skamarock W C and Kemp J B 1997 The resolution dependence of explicitly modeled convective systems; Mon. Weather Rev. 125 527-548.

William Gray M 1968 Global view of the origin of the tropical disturbances and storm; Mon. Weather Rev. 96 669-700.

MS received 6 October 2010; revised 23 March 2011; accepted 25 March 2011 